\title{
INTEREST-RATE VOLATILITY IN EMERGING MARKETS
}

\author{
Sebastian Edwards and Raul Susmel*
}

Abstract-We use high-frequency interest-rate data for a group of Latin American and Asian countries to analyze the behavior of volatility through time. We focus on volatility comovements across countries. Our analysis relies on univariate and bivariate switching volatility models. We compare the results from the switching models with those from rolling-standarddeviation models. We argue that the switching models are superior. Our results indicate that high-volatility episodes are, in general, short-lived, lasting from 2 to 7 weeks. We also find some evidence of interest-rate volatility comovements across countries.

\section{Introduction}

A FTER the Mexican crisis of 1994, most emerging economies experienced an increase in domestic interestrate volatility (see figure 1 for weekly data for Argentina, Brazil, Chile, Hong Kong, and Mexico). This phenomenon has affected policy debates in, at least, three ways. First, a number of authors have argued that increased interest-rate volatility is largely the result of "excessive" capital mobility; see Stiglitz (1999). According to this view the imposition of controls on capital inflows, similar to those used by Chile during 1991-1998, would help countries reduce externally induced financial instability (Krugman, 1999). Second, some authors have argued that increased interest-rate volatility is inherent in floating exchange rate regimes. This argument has, in fact, become central in recent discussions on the merits of dollarization in emerging economies; see Reinhart (2000). Third, the extent of markets' instabilityand, in particular, of changes in volatility - has played an important role in discussions on whether emerging markets have indeed been subject to contagion. Rigobon (2001), for instance, has argued that the simple analysis of the evolution of correlation coefficients through time may provide a misleading picture of contagion if the country in question experiences changes in volatility regime.

In this paper we use high-frequency data on domestic interest rates for five emerging countries-Argentina, Brazil, Chile, Hong Kong, and Mexico-to analyze the recent evolution of interest-rate volatility. We are particularly interested in five interrelated issues:

- Is it possible to statistically detect changes in interestrate volatility processes in these five countries?

- If so, how many volatility states can be identified?

- How common are high-volatility states? And for how long have they lasted?

- Do dates of high-volatility states (approximately) coincide across countries?

Received for publication May 2, 2000. Revision accepted for publication March 1, 2002.

*UCLA and NBER, and University of Houston, respectively.

This is a thoroughly revised version of a paper titled "Contagion and Volatility in the 1990s." We thank the editor and two referees for very helpful comments. We are grateful to Francis Longstaff and Pedro Santa Clara for helpful discussions.
- Can we statistically identify groups of countries that jointly experience high-volatility states?

The countries in our sample provide a very diverse set with respect to macroeconomic institutions, policies, and experiences. For example, during the period under consideration Chile and Brazil had controls on capital inflows, while the other three countries didn't. With regard to exchange-rate regimes, Argentina and Hong Kong had a currency board, Mexico has had a floating system since 1995, Chile floated within broad bands, and until January 1999 Brazil had a slowly crawling exchange-rate regime. Analyzing whether there are cross-country comovements of interest-rate volatility would help shed light on a number of important macroeconomics issues that are germane to the design of the new international financial architecture. Although we don't expect to solve current debates on contagion or on capital controls, we believe that the analysis presented in this paper provides important information on these issues.

We address the five questions asked above by using both univariate, as well as multivariate techniques. As a first step we implement a variant of Hamilton and Susmel's (1994) SWARCH methodology, to identify breakpoints in an ARCH model of the conditional variance. This model is well suited to address questions raised in recent contagion analyses: namely whether volatility and correlation coefficients significantly change due to a foreign event (Forbes and Rigobon, 1999). A particularly attractive property of the SWARCH approach is that it allows us to date periods of high volatility. We find that, in most (but not all) our countries the high-volatility states are rather short-lived. We also find that periods of high volatility tend to roughly coincide across some countries. We further explore the degree of comovement in volatility by developing a multivariate extension of the SWARCH model. Since this model is highly intensive in computing time, we restrict its application to pairs of countries. ${ }^{1}$

In contrast to our paper, most work on switching interestrate volatility has focused on one country. Hamilton (1989), for example, shows that the time series behavior of U.S. interest rates changed significantly during the Federal Reserve's 1979-1982 monetarist experiment. Ball and Torous (1995), Gray (1996), and Kalimipalli and Susmel (1999) have used switching models to analyze the volatility of U.S. interest rates.

\footnotetext{
${ }^{1}$ See Bennet and Kelleher (1988) and King and Wadhwani (1990). Other papers that deal with cross-country volatility include the studies on meteor showers by Engle and $\mathrm{Ng}$ (1993), Engle, Ito, and Lin (1990, 1992), and Hamano, Masulis, and Ng (1990), and the studies on time-varying correlations of equity markets by Longin and Solnik (1995) and Ramchand and Susmel (1998).
} 
Figure 1.-Nominal Interest Rates in Selected Latin American and East Asian Countries: First Differences (Weekly Data, 1994-1999)
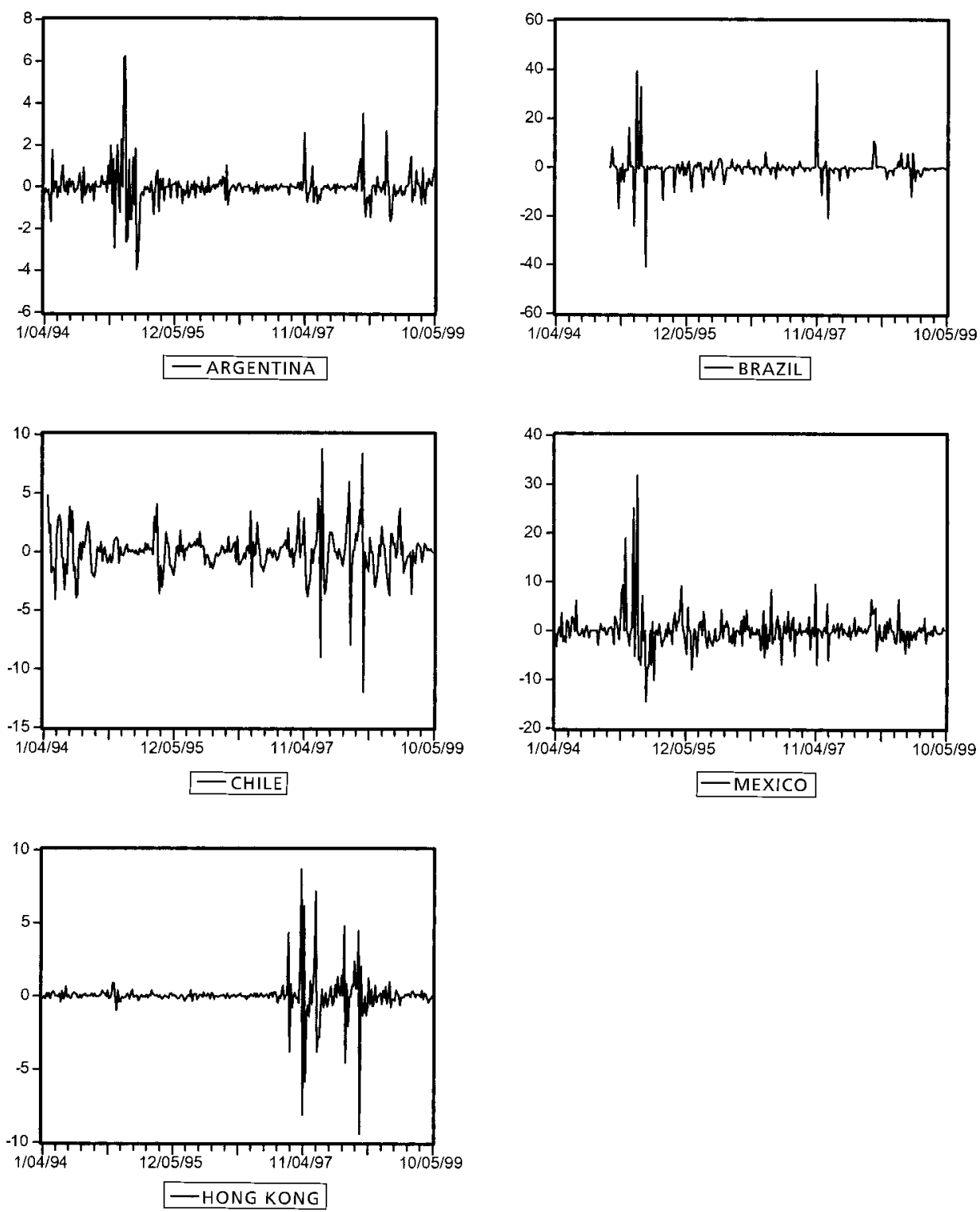

The paper is organized as follows: Section I is the introduction. In section II we discuss the data used in the analysis. In section III, we use univariate SWARCH models to analyze interest rate volatility in our five countries. Section IV contains the results for the multivariate case. Section $\mathrm{V}$ gives the conclusions.

\section{Interest-Rate Behavior in Selected Emerging}

Economies during the 1990s: A Preliminary Analysis

Our analysis deals with weekly data on the domestic nominal interest rate in Argentina, Brazil, Chile, Hong Kong, and Mexico during the 1990s. As in previous work on the subject, we concentrate on first differences (see, for

example, Gray, 1996, and Ghysels \& Ng, 1998). ${ }^{2}$ The data were taken from the Datastream data set and go back in time for as long as there is information. For Argentina we consider peso-denominated 30 day deposit rates (ARS), from April 5, 1991 to April 16, 1999. For Chile, we use the Chilean 30 day CD interest rate in pesos (CLP). The CLP sample starts on January 7, 1994. The Brazilian data (BRR) correspond to the CDI (middle) rate, and cover April 18,

\footnotetext{
${ }^{2}$ Concentrating on changes in interest rates avoids the problems associated with series that have a large, possibly unit root. All the series have large autoregressive coefficients. The Chilean interest rate has the smallest AR(1) coefficient (0.70), the Argentinean ARS interest has an AR(1) coefficient equal to 0.85 , and the rest of the series have AR(1) coefficients larger than 0.90. See Lanne (1999) for a discussion of near-unit roots in interest rates. See also Edwards (1998).
} 
Figure 2.-Interest Rates in Selected Emerging Countries: Levels (Weekly Data: 1994-1999)
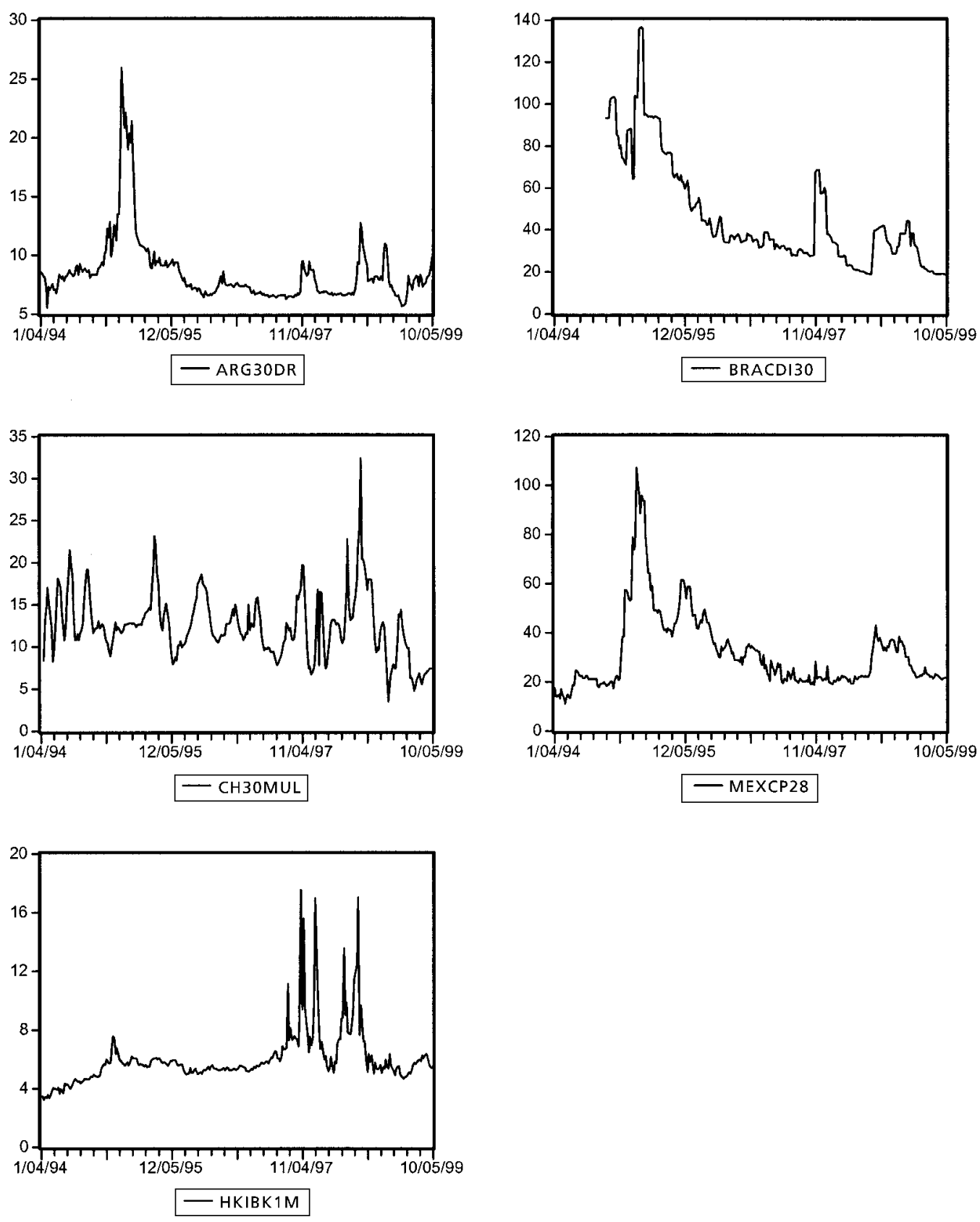

1994 through April 16, 1999. The Mexican interest rate is the 28 day deposit rate in pesos (MXP). The MXP interestrate sample starts on January 3, 1992, for a total of 381 observations. For Hong Kong, we use the interbank 30 day rate in Hong Kong dollars (HKD); we have a total of 433 observations.

In figure 1 we present the data in first differences; in figure 2 we present it in levels. The first-difference data clearly show that, in all five countries, interest rates have experienced changes in volatility during the period under study. Each case, however, presents its own peculiarities. In some countries (Hong Kong) volatility increases around

1997, in others (Argentina) volatility shifts several times from high to low and back to high. In yet others (Mexico) volatility appears to be high throughout most of the period.

Figure 2, on interest-rate levels, captures the financial upheaval of 1994-1999. Consider first the case of Argentina: interest rates on 30 day deposits exhibit spikes in the periods surrounding the Mexican (early 1995), East Asian (October-November 1997), Russian (August 1998), and Brazilian (January 1999) crises. Notice, however, that the magnitudes of these spikes are very different. Argentine interest rates were subject to the largest spike in the aftermath of the Mexican crises; the second largest was 
Table 1.-Univariate Statistics for Percentage Changes in Interest Rates

\begin{tabular}{|c|c|c|c|c|c|}
\hline Series & $\begin{array}{c}30 \text { Day } \\
\text { Argentina } \\
\text { ARS }\end{array}$ & $\begin{array}{c}30 \text { Day } \\
\text { Brazil } \\
\text { BRR }\end{array}$ & $\begin{array}{l}30 \text { Day } \\
\text { Chile } \\
\text { CLP }\end{array}$ & $\begin{array}{c}28 \text { Day } \\
\text { Mexico } \\
\text { MXP }\end{array}$ & $\begin{array}{c}30 \text { Day } \\
\text { Hong-Kong } \\
\text { HKD }\end{array}$ \\
\hline Mean & -0.269 & -0.265 & 0.242 & -0.022 & -0.078 \\
\hline S.d. & 8.876 & 9.881 & 15.077 & 8.977 & 11.507 \\
\hline Skewness & 0.922 & 3.490 & -1.325 & 1.088 & 1.767 \\
\hline Kurtosis & 12.73 & 21.636 & 7.726 & 4.713 & 16.99 \\
\hline JB normality test & $2865.81 *$ & 5060.45 & $764.43 *$ & $423.32 *$ & $5381.35^{*}$ \\
\hline $\mathrm{LB}(12)$ & $35.40 *$ & $14.06^{*}$ & $60.16 *$ & 12.33 & $39.36^{*}$ \\
\hline $\operatorname{LBS}(12)$ & $36.65^{*}$ & 0.49 & 10.74 & $62.24 *$ & $105.04 *$ \\
\hline $\begin{array}{l}\text { Hansen LR test } \\
\text { (1\% critical value) }\end{array}$ & $\begin{array}{c}5.43 \\
(4.36)\end{array}$ & $\begin{array}{l}7.69 \\
(2.54)\end{array}$ & $\begin{array}{l}2.03 \\
(2.05)\end{array}$ & $\begin{array}{c}7.49 \\
(4.62)\end{array}$ & $\begin{array}{c}5.82 \\
(4.15)\end{array}$ \\
\hline Number of obs. & 420 & 236 & 276 & 381 & 433 \\
\hline
\end{tabular}

Source: Computed by the authors from raw data obtained from Datastream.

* Significant at the $5 \%$ level.

associated with the Russian crisis. Although Chile's domestic interest rates also appear to have been affected by these crises, the magnitudes of the spikes appear to be smaller than those in the Argentine data. The data on Brazil show that, as the 1994 stabilization plan-the so-called real plan-became consolidated, interest rates experienced a declining trend. However, as in our other countries, Brazilian domestic interest rates did experience several jumps during the period under study. These appear to have happened at times that roughly coincide with the major currency crises of the period.

Not surprisingly, Mexican interest rates increased sharply in the aftermath of the Mexican peso crisis of December of 1994. However, as the figure shows, Mexican interest rates also appear to have been sensitive to major international crises. In fact, Mexico's interest rates were particularly affected by the collapse of the Russian ruble in August 1998. Finally, the data on Hong Kong show a small spike in interest rates in the period following the Mexican crisis of December 1994, a major jump at the time of the East Asian crisis and, again, a spike around the time of the Russian crisis.

In table 1 we present summary statistics for the first differences of our five interest rates. More specifically, this table contains information on the mean, standard deviation, skewness coefficient, kurtosis coefficient, Jarque-Bera normality test (JB), and Ljung-Box (1978) test (LB). These tests show the typical nonnormality of financial time series (note the JB test results). The high kurtosis coefficient is also typical of high-frequency financial time series, and it is behind the rejection of normality. The LB statistics suggest significant autocorrelation in the levels and in the squared levels, which, in turn, suggests a time-varying variance.

\section{A Univariate Analysis of Volatility Breakpoints}

\section{A. A Volatility Model}

Most studies on interest-rate volatility are based on the estimation of GARCH-type models (see Campbell, Lo, \&
MacKinlay, 1997). Although standard GARCH models are parsimonious and are able to capture the time-varying nature of volatility, they fail to capture structural shifts in the data that are caused by low-probability events, such as the Mexican crisis of 1994 or the East Asian crisis of 1997, among other. In this section we use the model of Hamilton and Susmel (1994) to explicitly model the dynamics of switching variance. Hamilton and Susmel (1994) expand the ARCH model to account for such structural breaks in data. In this paper we use a variant of Hamilton and Susmel's (1994) switching ARCH (SWARCH) model. More specifically, our $\operatorname{SWARCH}(K, q)$ model may be characterized as follows:

$$
\begin{aligned}
\Delta r_{t} & =a_{0}+a_{1} \Delta r_{t-1}+\varepsilon_{t}, \quad \varepsilon_{t} \mid I_{t-1} \sim N\left(0, h_{t}\right), \\
h_{t} / \gamma_{s_{t}} & =\alpha_{0}+\sum_{i=1} \alpha_{i} \varepsilon_{t-i}^{2} / \gamma_{s_{t-i}} \\
i & =1,2, \ldots, q, \text { and } s_{t}=1,2, \ldots, K,
\end{aligned}
$$

where the $\gamma$ 's are scale parameters that capture the change in regime, and the $\alpha$ 's are nonnegative. One of the $\gamma$ 's is unidentified, and hence $\gamma_{1}$ is set equal to $1 .^{3}$

In our model, changes in regime happen only in the variance. In terms of equations (1) and (2), this means that the parameters $a_{0}$ and $a_{1}$ are assumed to be constant. The parameters $\gamma_{s_{t}}$, on the other hand, are assumed to change. Our assumption of constant parameters $a_{0}$ and $a_{1}$ in the mean equation is, in fact, consistent with results reported in table 2 below, which indicate that a model that allows for switches in the mean is inferior to a SWARCH representation. The focus on a changing variance is an important difference between our work and more traditional models of contagion, which assume that shocks are transmitted through the mean and that the variance is constant.

The SWARCH model in equations (1) and (2) also requires a formulation of the probability law that causes the

${ }^{3}$ See Edwards and Susmel (2001) for an application of SWARCH models to equity markets in emerging nations. 
TABLE 2.-Estimation of AR(1)-SWARCH(3,1)

\begin{tabular}{|c|c|c|c|}
\hline Parameter & \multicolumn{2}{|c|}{ Argentina ARS } & Brazil BRR \\
\hline$a_{0}$ & \multicolumn{2}{|c|}{$-0.487(0.20)^{*}$} & $-0.087(0.03)$ \\
\hline$a_{1}$ & \multicolumn{2}{|c|}{$-0.193(0.05)^{*}$} & $0.016(0.05)$ \\
\hline$\alpha_{0}$ & \multicolumn{2}{|c|}{$6.804(1.14)^{*}$} & $0.131(0.03)^{*}$ \\
\hline$\alpha_{1}$ & \multicolumn{2}{|c|}{$0.266(0.09)^{*}$} & $0.068(0.10)$ \\
\hline$\alpha_{2}$ & \multicolumn{2}{|c|}{ - } & - \\
\hline$\gamma_{2}$ & \multicolumn{2}{|c|}{$3.841(0.84)^{\dagger}$} & $4.851(1.26)^{\dagger}$ \\
\hline$\gamma_{3}$ & \multicolumn{2}{|c|}{$35.31(9.85)^{\dagger}$} & $128.51(87.68)$ \\
\hline Likelihood & \multicolumn{2}{|c|}{-1352.4} & -220.3 \\
\hline Likelihood SWARCH $(3, q+1)$ & \multicolumn{2}{|c|}{-1351.5} & -220.2 \\
\hline $\mathrm{LB}(12)$ & \multicolumn{2}{|c|}{13.57} & 3.26 \\
\hline $\operatorname{LBS}(12)$ & \multicolumn{2}{|c|}{14.34} & 1.62 \\
\hline Likelihood SWARCH $(2,1)$ & \multicolumn{2}{|c|}{-1367.5} & -230.4 \\
\hline Likelihood SWARCH $(4,1)$ & \multirow{2}{*}{\multicolumn{2}{|c|}{$\begin{array}{l}-1358.9 \\
-1351.6\end{array}$}} & -219.9 \\
\hline Likelihood SWARCH $(K, q)-L-t$ & & & -220.1 \\
\hline Likelihood (mean only), $K=3$ & \multicolumn{2}{|c|}{-1435.3} & -318.4 \\
\hline Likelihood (mean and var.), $K=3$ & \multicolumn{2}{|c|}{-1366.1} & -222.1 \\
\hline Parameter & Chile CLP & Mexico MXP & Hong Kong HKD \\
\hline$a_{0}$ & $0.002(0.02)$ & $-0.522(0.27)^{*}$ & $0.171(0.22)$ \\
\hline$a_{1}$ & $0.160(0.07)^{*}$ & $0.066(0.04)$ & $-0.144(0.05)$ \\
\hline$\alpha_{0}$ & $0.189(0.03)^{*}$ & $9.284(2.54)^{*}$ & $9.064(1.25)$ \\
\hline$\alpha_{1}$ & $0.429(0.13)^{*}$ & - & $0.012(0.05)$ \\
\hline$\gamma_{2}$ & $3.068(1.62)$ & $3.971(1.10)^{\dagger}$ & $7.671(1.31)^{\dagger}$ \\
\hline$\gamma_{3}$ & $20.957(11.51)$ & $25.475(8.02)^{\dagger}$ & $79.168(24.89)^{\dagger}$ \\
\hline Likelihood & -288.7 & -1287.0 & -1441.6 \\
\hline Likelihood SWARCH $(3, q+1)$ & -288.7 & -1286.8 & -1441.4 \\
\hline $\mathrm{LB}(12)$ & 10.50 & 7.14 & 6.78 \\
\hline LBS(12) & 2.74 & $40.94 *$ & 1.17 \\
\hline Likelihood SWARCH $(2,1)$ & -290.2 & -1294.9 & -1484.1 \\
\hline Likelihood SWARCH $(4,1)$ & -288.0 & -1283.5 & -1436.3 \\
\hline Likelihood SWARCH $(K, q)-L-t$ & -288.6 & -1281.9 & -1430.3 \\
\hline Likelihood (mean only), $K=3$ & -358.1 & -1362.2 & -1651.9 \\
\hline Likelihood (mean and var.), $K=3$ & -296.2 & -1295.8 & -1446.7 \\
\hline
\end{tabular}

Standard errors in parenthesis.

* Significant at the $5 \%$ level.

* Significantly different than 1 at the $5 \%$ level.

$\Delta r_{t}=a_{0}+a_{1} \Delta r_{t-1}+\varepsilon_{t}, \varepsilon_{t} \mid I_{t-1} \sim N\left(0, h_{t}\right), h_{t} / \gamma_{s t}=\alpha_{0}+\alpha_{1} \varepsilon_{t-1}^{2} / \gamma_{s_{t-1}}$.

economy to switch among regimes. One simple specification is that the state of the economy is the outcome of a $K$-state Markov chain that is independent of $r_{t}$ for all $t$ :

$$
\begin{aligned}
\operatorname{Prob}\left(s_{t}\right. & \left.=j \mid s_{t-1}=i, s_{t-2}=k, \ldots, r_{t}, r_{t-1}, r_{t-2}, \ldots\right) \\
& =\operatorname{Prob}\left(s_{t}=j \mid s_{t-1}=i\right)=p_{i j} .
\end{aligned}
$$

In this model, the transition probabilities, the $p_{i j}$ 's are constant. If, for example the economy was in a highvolatility state last period $\left(s_{t}=2\right)$, the probability of changing to the low-volatility state $\left(s_{t}=1\right)$ is a fixed constant $p_{21}$. This switching model is estimated using maximum likelihood, as proposed by Hamilton (1989). During the estimation, some of the parameters hit the nonnegativity constraint. To get convergence, we set these parameters equal to zero.

Hamilton (1989) has shown that as a byproduct of the maximum likelihood estimation, we can make inferences about the particular state of the corresponding interest rate at any date. The filter probabilities, $p\left(s_{t} \mid r_{t}, r_{t-1}, \ldots, r_{t-3}\right)$, denote the conditional probability that the state at date $t$ is $s_{t}$. These probabilities are conditional on the values of $r$ observed through date $t$. The smooth probabilities, $p\left(s_{t} \mid r_{T}, r_{T-1}, \ldots, r_{T-3}\right)$, on the other hand, are inferences about the state at date $t$, based on data available through some future date $T$ (end of sample). For a two-state specification, for example, the smooth probabilities at time $t$ are represented by a $2 \times 1$ vector denoting the probability estimates of the two states. That is, the smooth probabilities represent the ex post inference made by an econometrician about the state of the security at time $t$, based on the entire time series.

\section{B. $\operatorname{SWARCH}(3,1)$ Estimates}

We estimated, for each of our interest-rate series, a simple $\operatorname{AR}(1)-\operatorname{GARCH}(1,1)$ model. As mentioned above, to avoid the problems associated with nonstationary time series, we work with first differences. ${ }^{4}$ The results find significant $\mathrm{ARCH}$ effect for all the series and high-volatility

\footnotetext{
${ }^{4}$ We also worked with levels for interest rates. We used a specification where the AR(1) coefficient is state-dependent, allowing in at least one of the states for interest rates to be nonstationary. The results are similar to the results presented in this section. Moreover, we find that the volatility
} 
TABle 3.-Estimation of AR(1)-SWARCH(3,1): Estimation of THE TRANSITION PROBABILITY MatRIX

\begin{tabular}{|c|c|c|c|c|c|c|c|c|}
\hline \multicolumn{4}{|c|}{ Argentina (ARS) } & & \multicolumn{4}{|c|}{ Brazil (BRR) } \\
\hline $\begin{array}{l}.978 \\
(.01)\end{array}$ & & $\begin{array}{l}.013 \\
(.01)\end{array}$ & $\begin{array}{l}.000 \\
(.01)\end{array}$ & & $\begin{array}{l}.923 \\
(.03)\end{array}$ & $\begin{array}{l}.114 \\
(.07)\end{array}$ & & $\begin{array}{l}.001 \\
(.01)\end{array}$ \\
\hline $\begin{array}{l}.001 \\
(.01)\end{array}$ & & $\begin{array}{l}.932 \\
(.03)\end{array}$ & $\begin{array}{l}.199 \\
(.08)\end{array}$ & & $\begin{array}{l}.077 \\
(.04)\end{array}$ & $\begin{array}{l}.807 \\
(.08)\end{array}$ & & $\begin{array}{l}.999 \\
(.55)\end{array}$ \\
\hline $\begin{array}{l}.022 \\
(.01)\end{array}$ & & $\begin{array}{l}.055 \\
(.02)\end{array}$ & $\begin{array}{l}.801 \\
(.08)\end{array}$ & & $\begin{array}{l}.000 \\
(.01)\end{array}$ & $\begin{array}{l}.078 \\
(.05)\end{array}$ & & $\begin{array}{l}0.0 \\
-\end{array}$ \\
\hline \multicolumn{3}{|c|}{ Chile (CLP) } & \multicolumn{3}{|c|}{ Mexico (MXP) } & \multicolumn{3}{|c|}{ Hong Kong (HKD) } \\
\hline $\begin{array}{l}.980 \\
(.02)\end{array}$ & $\begin{array}{l}.000 \\
(.01)\end{array}$ & $\begin{array}{l}.173 \\
(.16)\end{array}$ & $\begin{array}{l}.840 \\
(.06)\end{array}$ & $\begin{array}{l}.025 \\
(.02)\end{array}$ & $\begin{array}{l}.138 \\
(.35)\end{array}$ & $\begin{array}{c}.985 \\
(.01)\end{array}$ & $\begin{array}{c}.001 \\
(.07)\end{array}$ & $\begin{array}{l}.000 \\
(.01)\end{array}$ \\
\hline $\begin{array}{l}.001 \\
(.01)\end{array}$ & $\begin{array}{c}.929 \\
(.07)\end{array}$ & $\begin{array}{l}.178 \\
(.24)\end{array}$ & $\begin{array}{l}.027 \\
(.05)\end{array}$ & $\begin{array}{l}.838 \\
(.08)\end{array}$ & $\begin{array}{c}.021 \\
(.04)\end{array}$ & $\begin{array}{l}.001 \\
(.01)\end{array}$ & $\begin{array}{l}.982 \\
(.08)\end{array}$ & $\begin{array}{l}.058 \\
(.06)\end{array}$ \\
\hline $\begin{array}{l}.020 \\
(.01)\end{array}$ & $\begin{array}{l}.072 \\
(.05)\end{array}$ & $\begin{array}{c}.649 \\
(.11)\end{array}$ & $\begin{array}{c}.139 \\
(.06)\end{array}$ & $\begin{array}{l}0.0 \\
-\end{array}$ & $\begin{array}{c}.839 \\
(.07)\end{array}$ & $\begin{array}{c}.008 \\
(.01)\end{array}$ & $\begin{array}{c}.008 \\
(.01)\end{array}$ & $\begin{array}{c}.942 \\
(.06)\end{array}$ \\
\hline
\end{tabular}

Standard errors in parentheses. persistence. For four of the six series, shocks to the conditional variance are highly persistent over time. ${ }^{5}$ Lamoureux and Lastrapes (1990), Cai (1994), and Hamilton and Susmel (1994) argue that the observed high persistence of shocks to the conditional variance is a sign of structural change in variance.

Before estimating the SWARCH model, we test the null hypothesis of no switching. To do so, we use the likelihood ratio test proposed by Hansen (1992, 1994). A likelihood ratio test of this null hypothesis does not have the usual limiting $c h i$-squared distribution, because the parameters $p_{i j}$ are unidentified under the null hypothesis. Hansen (1992) proposes a test, based on the theory of empirical processes, that is able to provide an upper bound on the asymptotic distribution of standardized likelihood ratio statistics, even

states are determined by the variance, and not by the different $\mathrm{AR}(1)$ coefficients.

${ }^{5}$ Again, it is usual to observe, in high-frequency financial series, the so-called integrated GARCH model, where $\alpha_{1}+\beta_{1}=1$.

Figure 3.-SWARCH $(3,1)$ Estimates for Argentina Peso-Denominated Interest Rates
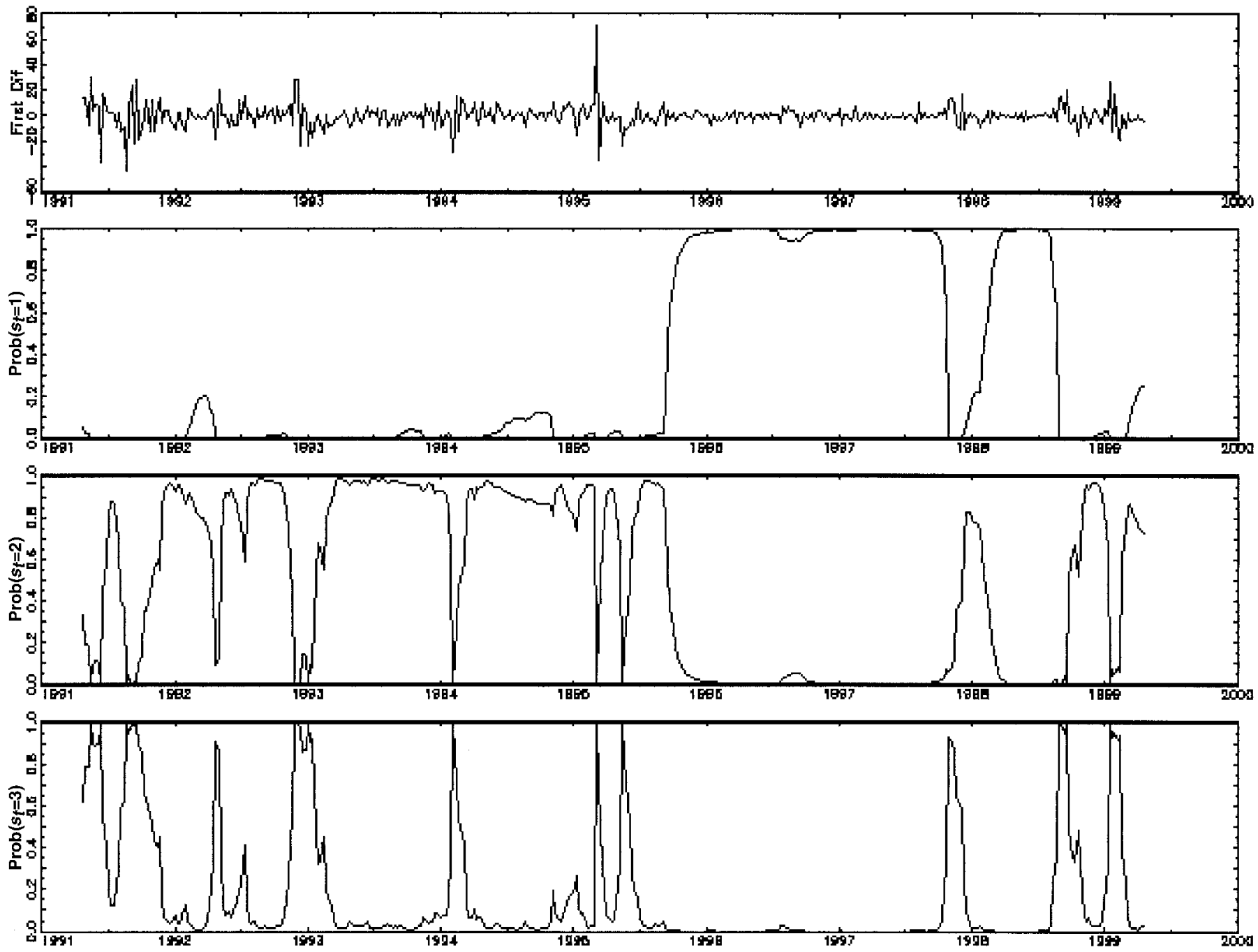
Figure 4.-SWARCH $(3,1)$ Estimates for Brazil Nominal Interest Rates
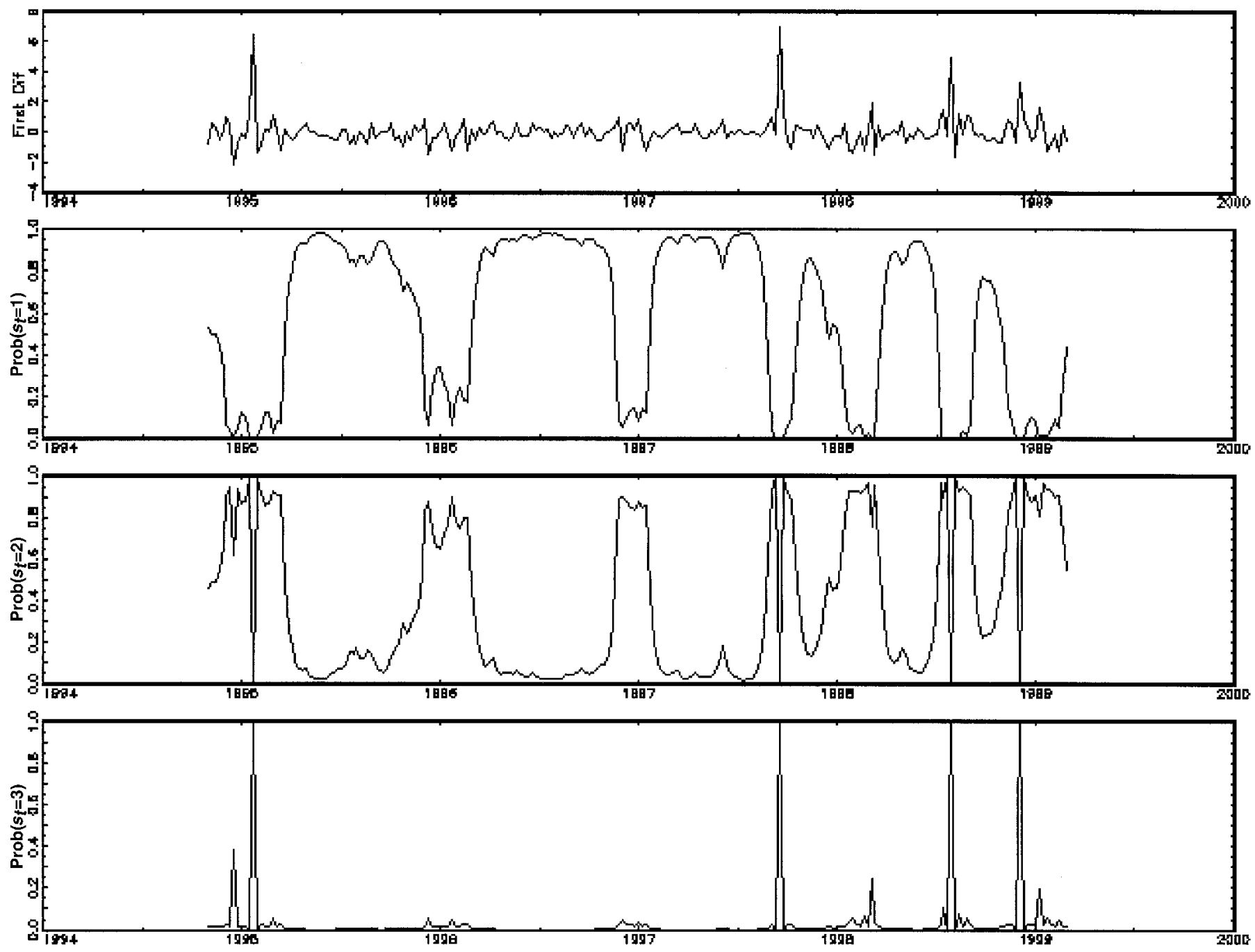

when conventional regularity conditions (such as unidentified parameters) are violated. ${ }^{6}$ We compute Hansen's test for all our domestic-currency interest-rate series under the null hypothesis of no regime switching. In this computation we

\footnotetext{
${ }^{6}$ To get around the problem of no identified parameters under the null, Hansen (1994) defines a function $q_{t}(\zeta)=L_{t}[\zeta, \lambda(\zeta)]-L_{t}\left[\zeta_{0}, \lambda\left(\zeta_{0}\right)\right]$, where $L_{t}[\zeta, \lambda(\zeta)]$ represents the conditional log likelihood of the $t^{\text {th }}$ observation when evaluated at $\zeta$ and $\lambda(\zeta)$. The parameters $\zeta$ and $\lambda$ represent a partition of the parameter space. For the two-state case $\zeta=$ $\left(p_{11}, p_{22}, \gamma_{2}\right)$ and $\lambda=\left(a_{0}, a_{1}, \alpha_{0}, \alpha_{1}\right)$. Under the null hypothesis of no regime switching, $\zeta=\zeta_{0}=(1,0,1)$. We investigated a grid containing 345 possible parameters for $\zeta$ under the alternative hypothesis, with $Z$ consisting of these 345 possibilities considered. For Hong Kong, for example, we use $(99,0.95,0.9,0.5,0.4,0.2)$ as a grid for $p_{11}$ and $p_{22}$. For $\gamma_{2}$, the grid was set at $(2,3,4,6,7,9,11)$. For any $\zeta, \lambda(\zeta)$ is estimated by maximizing the likelihood with respect to $\lambda$, given $\zeta$. Hansen (1994) proposes the following standardized test: $L R=\max _{\zeta \in Z} T m q(\zeta) /$ $\left\{\Sigma_{t}\left[q_{t}(\zeta)-m q(\zeta)\right]^{2}\right\}^{1 / 2}$, where $m q$ is the mean of $q_{t}$. Hansen shows that, if the null hypothesis of no regime change is true, then for large samples the probability that $L R$ will exceed a critical value $z$ is less than the probability that a Monte Carlo simulated statistic would exceed the same value $z$.
}

used a four-lag Newey-West correction. Notice that under our model, the mean parameters are not subject to change in regime. The standardized likelihood ratio tests and their corresponding simulated $1 \%$ critical values are reported in table 1 . For all the series, the null hypothesis of no regime switch can be rejected at the 5\% level. The Hansen test for Chile's CLP rate provides a standardized likelihood ratio test of 2.03, which is slightly lower than the simulated $1 \%$ upper bound critical value of 2.05 .

Once the hypothesis of no regime switch has been rejected, we move to the next step in the analysis. Here we use a variant of the SWARCH model of Hamilton and Susmel (1994) to identify periods of unusually high volatility. We estimated SWARCH models with $K=2$ to 4 states and $q=$ 0 to 3 autoregressive terms. We also considered SWARCH models with asymmetric effects, as developed by Glosten, Jaganathan, and Runkle (1993), and with $t$-distributed conditional errors. Our results suggest that either two- or three-state SWARCH models may be appropriate for the 
Figure 5.-SWARCH $(3,1)$ Estimates for Chile Nominal Interest Rates
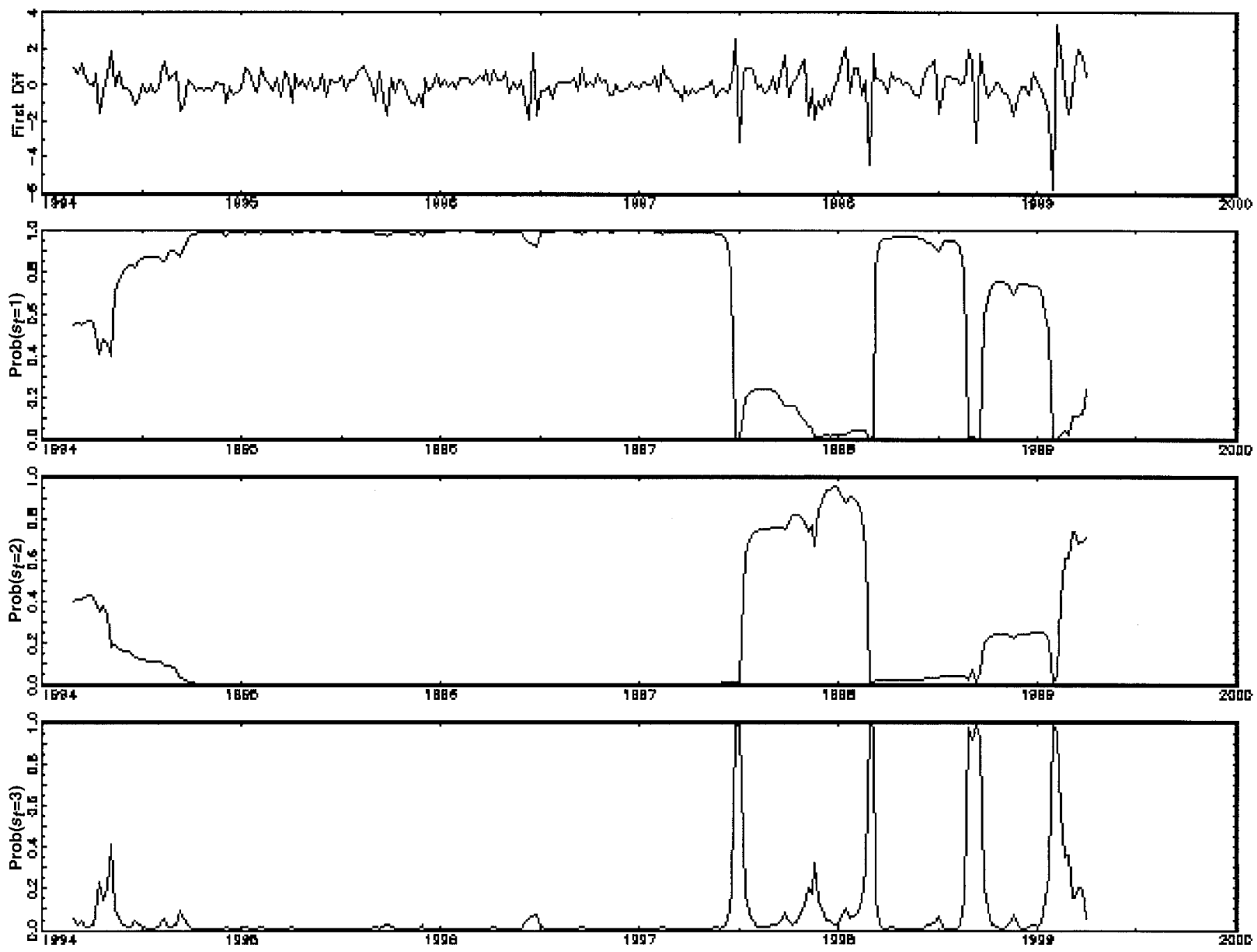

majority of our interest-rate series. ${ }^{7}$ In the rest of this section, for reasons of space, we focus on the case of three volatility states. The reader should keep in mind, however, that the results discussed here largely apply also to the case of two states (high and low volatility) only.

The results from the estimation of the three-state volatility SWARCH models are reported in table 2 . Several interesting findings emerge from this table. First, for each of our five interest rates it is possible to distinguish a low, a moderate, and a high volatility state. Second, for all the series we notice that using the $\operatorname{SWARCH}(K, q)$ model causes the ARCH effects to be reduced. Third, the switching

\footnotetext{
${ }^{7}$ Standard likelihood ratios reject, with the exception of Chile, the null hypothesis of a two-state model against the three-state model. Standard likelihood ratio tests, however, cannot be used, because the parameters $p_{i j}$ for the third state are unidentified under the null hypothesis of two states. Precise Hansen (1992) tests are computationally expensive in this case, because of the large number of parameters needed for the grid. For Argentina, preliminary (that is, not very fine grid) tests are unable to reject the null hypothesis of two states against the alternative hypothesis of three states.
}

parameters, the $\gamma_{i}$ 's, are significantly different from 1 in all three series. Fourth, likelihood ratio tests $[\operatorname{SWARCH}(K$, $q)$-L] show no evidence for an asymmetric effect of negative news on conditional volatility as suggested by the model proposed by Glosten, Jaganathan, and Runkle (1993). ${ }^{8}$

We are particularly interested in the results for the estimated $\gamma_{i}$ 's. As argued by Hamilton and Susmel (1994), $\gamma_{j}$ provides an estimate of the ratio of the conditional variance in state $j$, relative to the low-volatility state. That is, in our three-state case, $\gamma_{2}$ provides information on how high is moderate volatility relative to low volatility. Likewise, $\gamma_{3}$ captures the estimated ratio of high relative to low volatility. For example, for Argentina's ARS nominal interest rate, the moderate volatility is on average around 4 times higher than the low volatility, and the high volatility is on average 35 times higher than the low volatility. Interestingly enough,

\footnotetext{
${ }^{8}$ In Edwards and Susmel (2001) we estimated a more simple two-state SWARCH model for equity returns in a group of emerging countries.
} 
Figure 6.-SWARCH $(3,1)$ Estimates for Hong Kong Nominal InTERest Rates
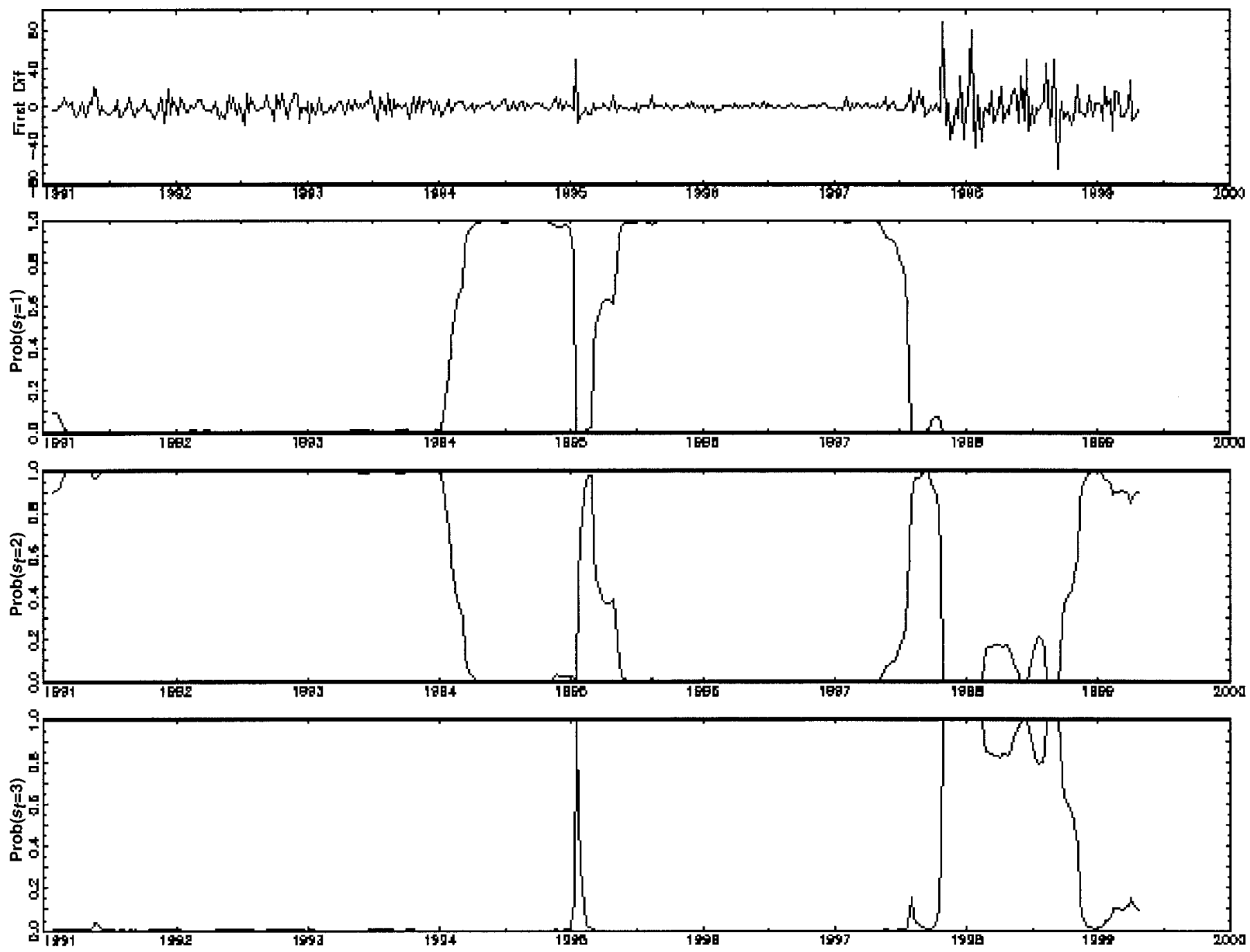

the largest ratio of average high to low state is in Brazil (128); Hong Kong follows closely, with an estimated $\gamma_{3}$ of 79. Chile, on the other hand, has the lowest estimated $\gamma_{3}$, with a still remarkable value of 20 .

The estimates of the transition matrix are reported in table 3 . In general, the estimates of the parameters $p_{11}$ and $p_{22}$ have narrow confidence intervals, as expected, since the low and medium volatility states are the states with the highest persistence. The estimates for the transition probability $p_{33}$ have wider confidence intervals, especially for Chile. Note that the estimate for Brazil is set equal to 0 , because during the maximum likelihood estimation it hit the nonnegativity constraint. That is, for Brazil, the high-volatility state is expected to last only one week.

We are interested in checking if the three-state regimes are also influenced by the mean. We fit two different standard Hamilton (1989) models, with three states: The first model allows only for mean switching, whereas the second model allows for simultaneous mean and variance switching. In table 2, we report the likelihood function of each of these two models. For the first one, we find that the first and third states tend to play the role of dummy variables, identifying outliers, and that the fit of the model is inferior to the SWARCH model. When we allow for simultaneous mean and variance switching we find that the states are primarily driven by variance switching, not mean switching. Moreover, the states, determined by the smoothed probabilities, are similar to the states that were determined by the SWARCH model.

The first panel of figure 3 plots weekly changes in Argentina's peso-denominated interest rates (ARS); the other three panels plot the smoothed probabilities, $\operatorname{Prob}\left(s_{t}=i \mid r_{T}, r_{T-1}, \ldots, r_{-3}\right)$, for the change in nominal interest rates. The second panel plots the smoothed probability that the economy was in state 1 (low volatility) at time $t$. The third panel plots the smoothed probability that the economy was at state 2 (moderate volatility) at time $t$. And the fourth panel plots the smoothed probability that the economy is at state 3 (high volatility) at time $t$. We follow Hamilton's (1989) proposed method for dating regime 
Figure 7.-SWARCH $(3,1)$ Estimates for Mexico Nominal Interest Rates
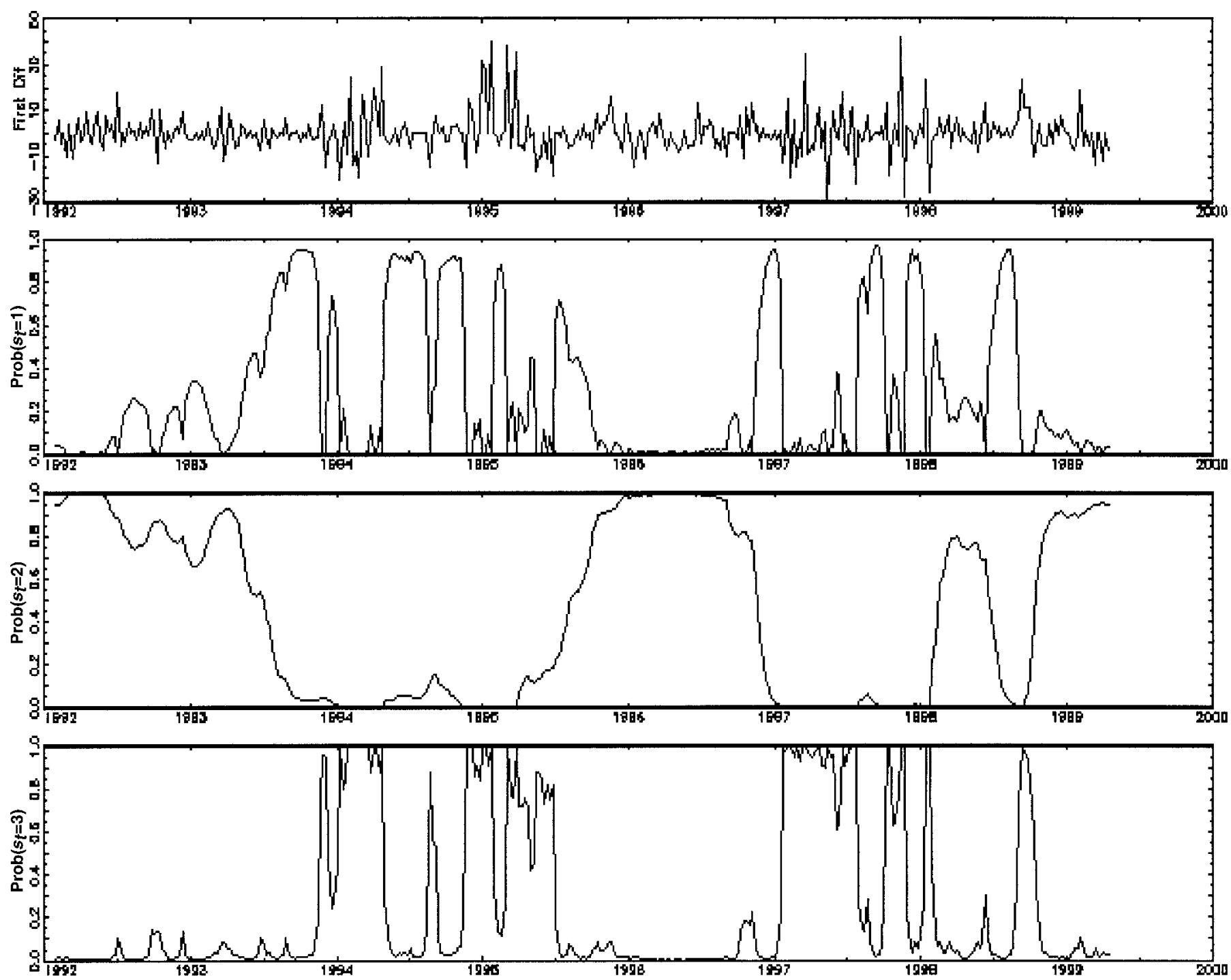

switches. According to this procedure, an observation belongs to state $i$ if the smoothed probability $\operatorname{Prob}\left(s_{t}=\right.$ $\left.i \mid r_{T}, r_{T-1}, \ldots, r_{-3}\right)$ is larger than 0.5. Changes in ARS interest rates switch between the moderate-volatility state and the high-volatility state during the first four and a half years of our sample. In the second half of 1995, ARS

Table 4.-Identifying High-Volatility Episodes Around Major CURRENCY CRISES: DECEMBER 1994-APRIL 1999

\begin{tabular}{|c|c|c|c|c|}
\hline Country & $\begin{array}{l}\text { Mexican } \\
\text { Crisis } \\
\text { 12/30/94 }\end{array}$ & $\begin{array}{c}\text { Asian } \\
\text { Crisis } \\
\text { 10/24/97 }\end{array}$ & $\begin{array}{c}\text { Russian } \\
\text { Crisis } \\
8 / 13 / 98\end{array}$ & $\begin{array}{c}\text { Brazilian } \\
\text { Crisis } \\
1 / 15 / 99\end{array}$ \\
\hline Argentina & 3/10/95 (5) & $10 / 31 / 97(6)$ & 8/28/98 (5) & $1 / 15 / 99(5)$ \\
\hline Brazil & 3/10/95 (1) & 10/31/97 (1) & 9/11/98 (1) & $1 / 15 / 99$ (1) \\
\hline Chile & $\mathrm{xxx}$ & 3/06/98 (2) & 9/04/98 (4) & 2/05/99 (3) \\
\hline Mexico & 12/30/94 (25) & 10/24/97 (7) & 9/04/98 (5) & $\mathrm{xxx}$ \\
\hline Hong Kong & $1 / 13 / 95(2)$ & \multicolumn{2}{|c|}{$10 / 24 / 97(52)$} & $\mathrm{xxx}$ \\
\hline
\end{tabular}

Each entry provides a starting date for the high-volatility state (third state) and the number of weeks the economy was in that state during each crisis. $\mathrm{xxx}$ means the economy was not in the third state during the given crisis. interest rates change to the low volatility for more than two years. Then, during the last quarter of 1998, there is a short shift towards high volatility, followed by another three months in the moderate-volatility state. Finally, during the third quarter of 1998, there is a new shift towards high and then moderate volatility.

Figure 3 suggests that since late 1994 the spells of Argentina's interest rate ARS in the high-volatility state correspond (roughly) to foreign (exogenous) events. For example, after 1994 the moves to the high-volatility state coincide with the Mexican crisis, the Asian crisis, the Russian crisis, and the Brazilian crisis, respectively. These results may suggest that indeed Argentina was subject to some form of volatility spillover during these crises. We analyze this hypothesis in greater detail in the next section, where we use a multivariate switching volatility model to investigate whether we can reject the hypothesis of volatility comovements and independence in pairs of countries. It 
Figure 8.-Rolling-Volatility Estimates for Mexico and Hong Kong Nominal Interest Rates
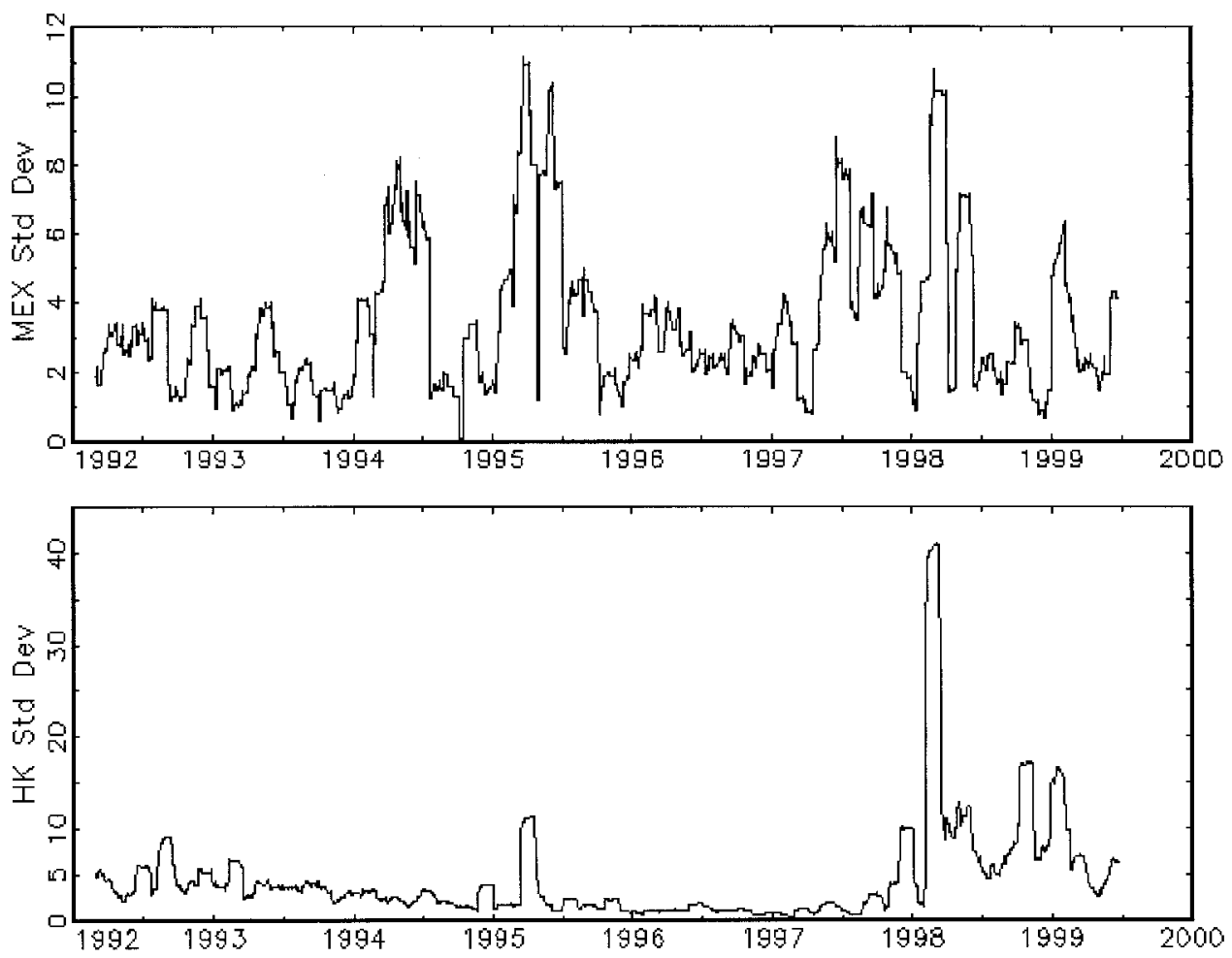

Window: 25 weeks.

Figure 9.-Rolling-Volatility Estimates for Brazil and ARgentina Nominal Interest Rates
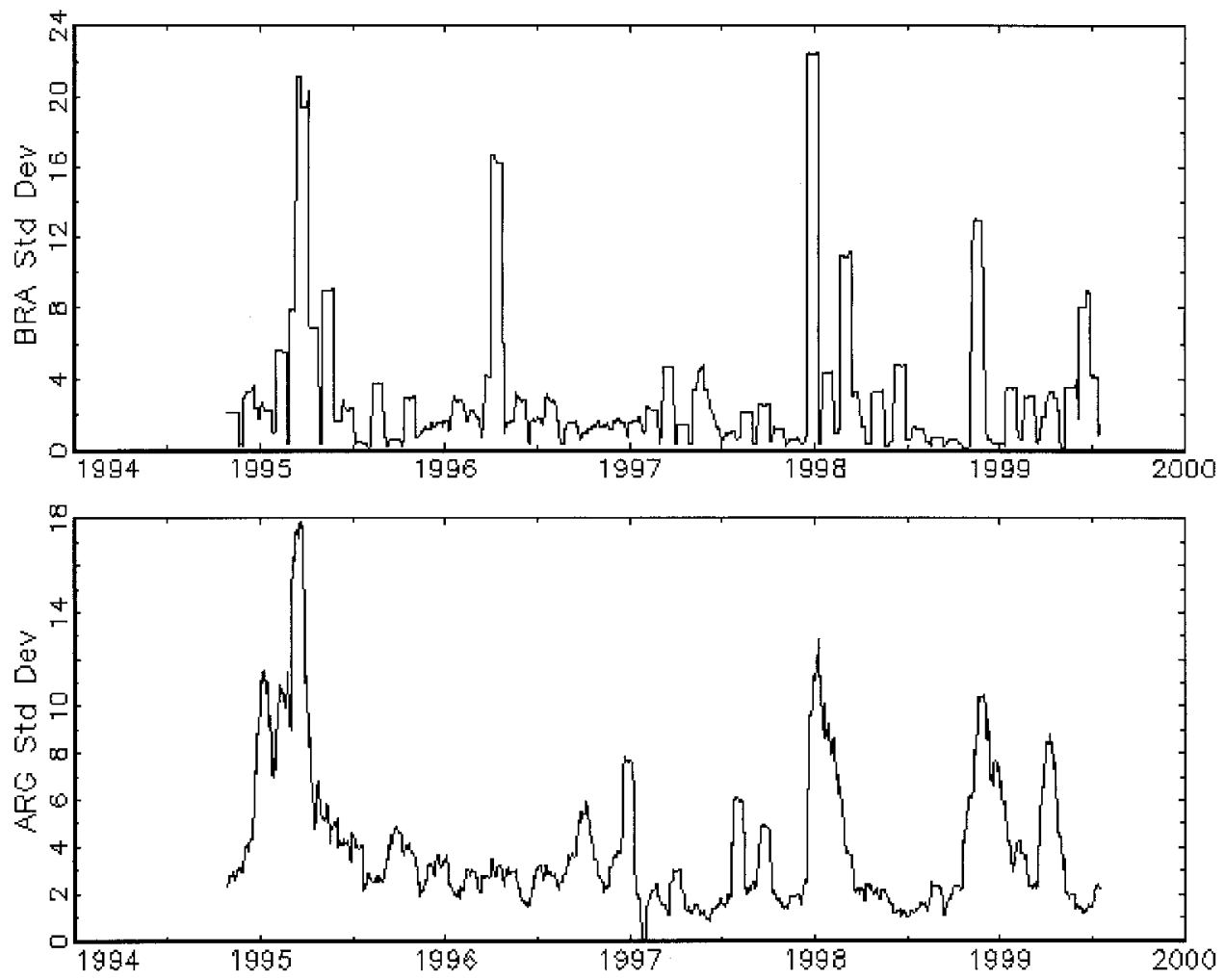

Window: 15 weeks. 
Figure 10.-Bivariate SWARCH Model: Mexico-Argentina
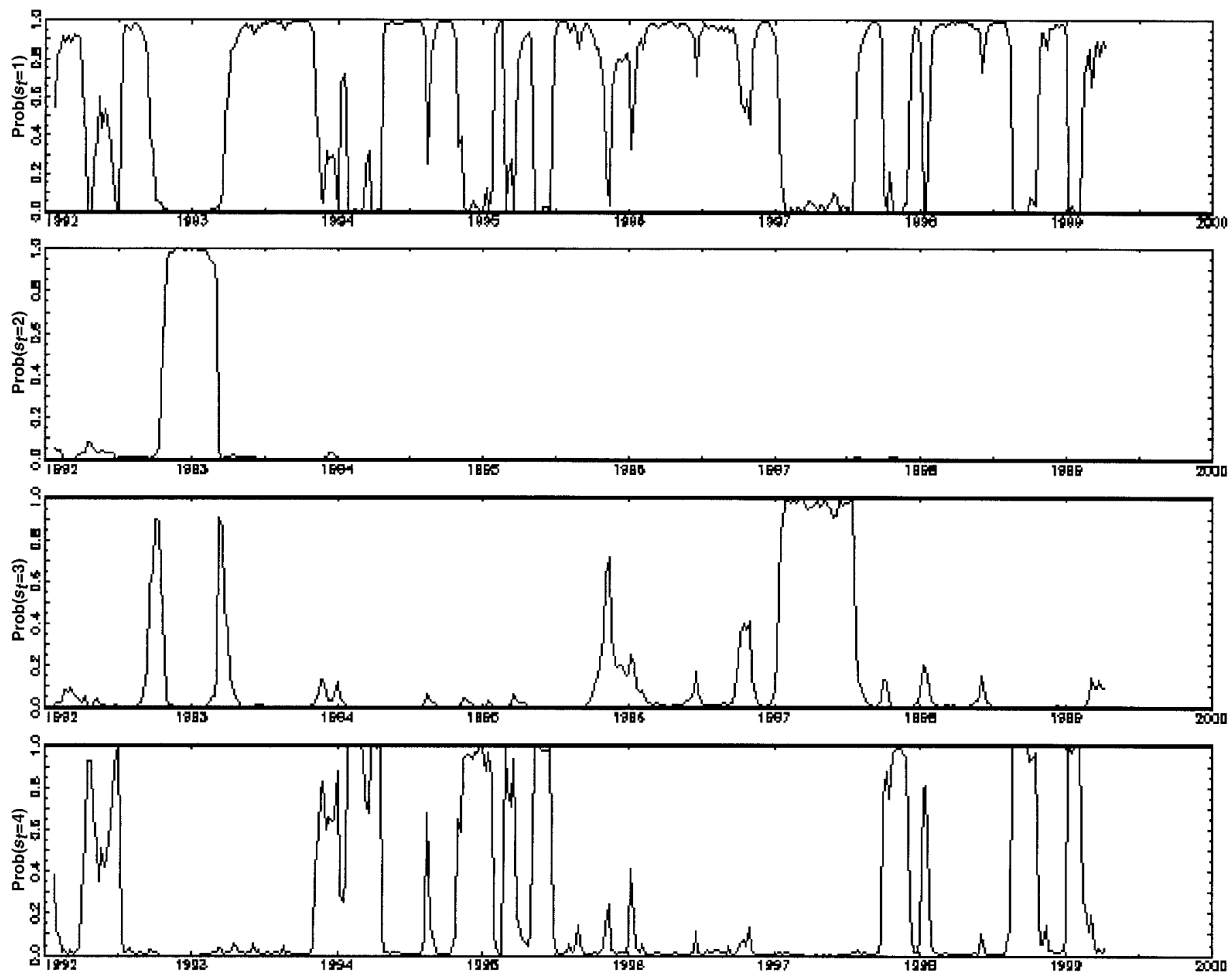

is important to notice, however, that the high-volatility state detected in 1991, 1992, and mid-1993 cannot be attributed-or at least not easily - to external events. We interpret this period of high instability as reflecting the low degree of credibility enjoyed by Argentina's currency board during its early years. ${ }^{9}$

Figures 4 through 7 correspond to the results obtained for our other four countries. The results are quite interesting and show that for Brazil and Chile the periods of high volatility are relatively short-lived. Moreover, Chile does not appear to have suffered an increase in interest-rate volatilitydefined as a move to the high state-during late 1994 or early 1995. This suggests, quite strongly we believe, that Chile was rather immune to instability generated by the Mexican tequila crisis. Starting in late 1997, however, Chile

\footnotetext{
${ }^{9}$ See Ruge-Murcia (1995) for a credibility interpretation of switching
} states along the lines discussed here. underwent several moves to the high-volatility state. These appear to correspond to periods of enhanced financial upheaval in the global economy: the intensification of the Asian crisis in late 1997, the Russian collapse in August 1998, and the Brazilian crisis of January 1999.

In the case of Mexico, our results in figure 7 suggest a high-volatility state that extends from late 1994 through most of the first half of 1995. This, of course, corresponds to the Mexican peso crisis and, for Mexico, responds to domestic upheaval. As figure 6 shows, Hong Kong shifts to a high-volatility state in late October 1997, and stays in that state for almost a year. The beginning of it corresponds to the attack on the Hong Kong currency board and to the heightening of the East Asian crisis. The very long period during which Hong Kong was in the high volatility state is surprising, and does not correspond to what we observe in the other crisis countries in the sample (Mexico and Brazil). 
Figure 11.-Bivariate SWARCH Model: MeXico-BraZIL
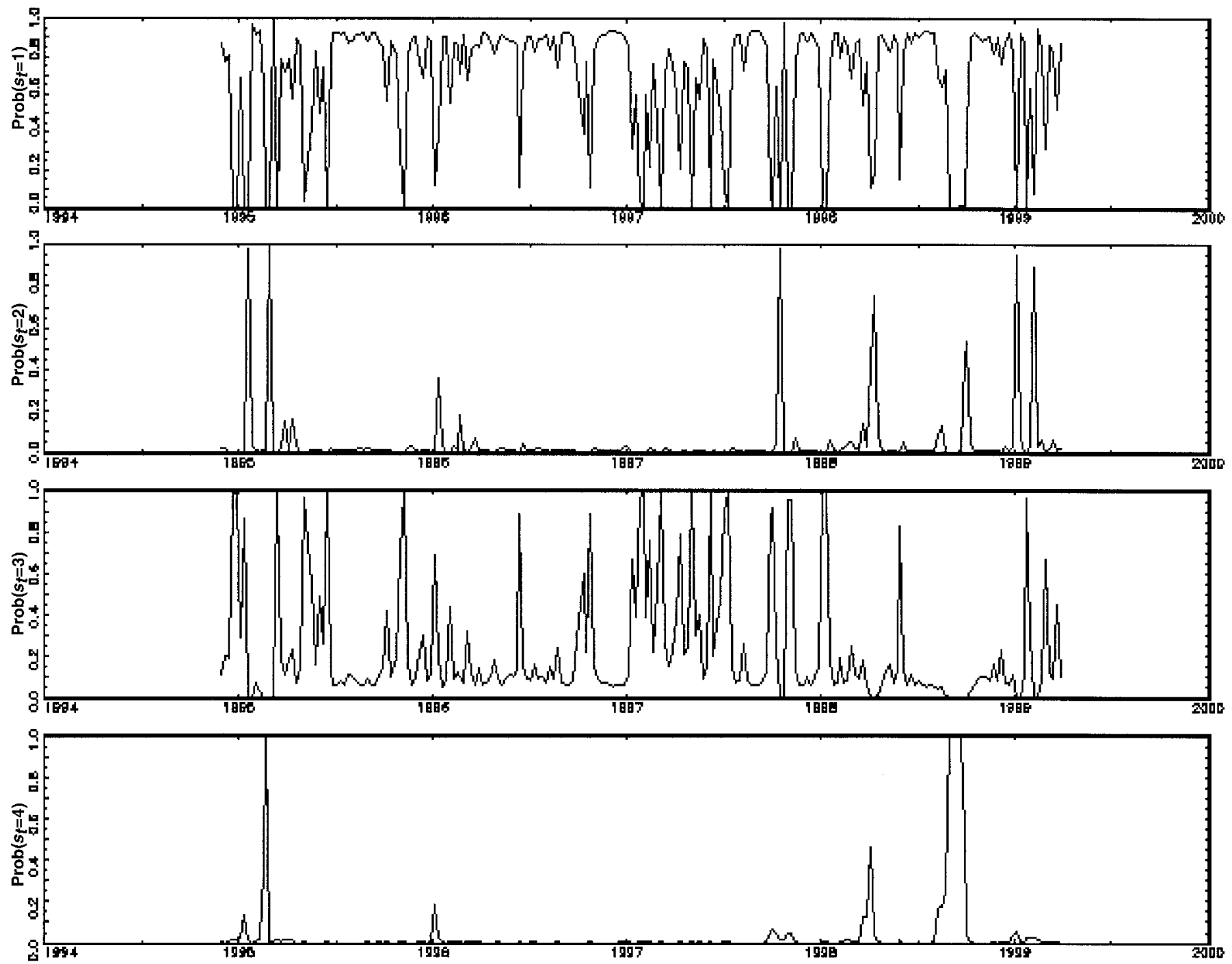

Figures 3 through 5 distinctly show that Argentina, Brazil, Chile, and Mexico shifted to a high-interest-ratevolatility state sometime between late August and mid September 1998. This coincides with the Russian crisis and suggests that there was a fairly rapid transmission of financial instability across emerging economies. Because Hong Kong stayed continuously in a high volatility state after October 1997, we are unable to discern whether the Russian crisis had an impact on Hong Kong's short-term interest rates. Finally, it is interesting to note from these figures that, while Argentina and Chile experienced a shift to high volatility in the period immediately following the Brazilian crisis of 1999, Hong Kong and Mexico did not suffer increased interest-rate instability at the time. ${ }^{10}$

\footnotetext{
${ }^{10}$ In order to quantify the uncertainty around the smoothed probabilities, we simulated the distribution for each series 200 times and estimated the transition probabilities and smoothed probabilities. For Argentina, Mexico, and Hong Kong, the simulated smoothed probabilities and the actual smoothed probabilities are close, with an average correlation above 0.91 .
}

In table 4 we present a summary of our findings on the extent and duration of high volatility in the periods surrounding the Mexican, East Asian, Russian, and Brazilian currency crises of the 1990s. For each of our countries each entry in this table provides a starting date for the highvolatility state, as well as the number of weeks domestic interest rates stayed in that state. It is particularly suggestive that our countries experienced a significant increase in volatility in the period following a major crisis. It is also interesting (and reassuring) to note that the crises countries themselves are indeed the first to experience a shift to the high-volatility state. The fact that the dates of high volatility states roughly coincide is suggestive, but does not constitute statistical evidence in favor of either the volatility

For Brazil and Chile, the average correlation between the simulated smoothed probabilities and the actual smoothed probabilities was 0.85 and 0.80 . Using the simulated values, the third state was estimated with lower precision, especially for Brazil and Chile, as expected, given their estimated $p_{33}$. 
Figure 12.-Bivariate SWARCH Model: Mexico-Chile
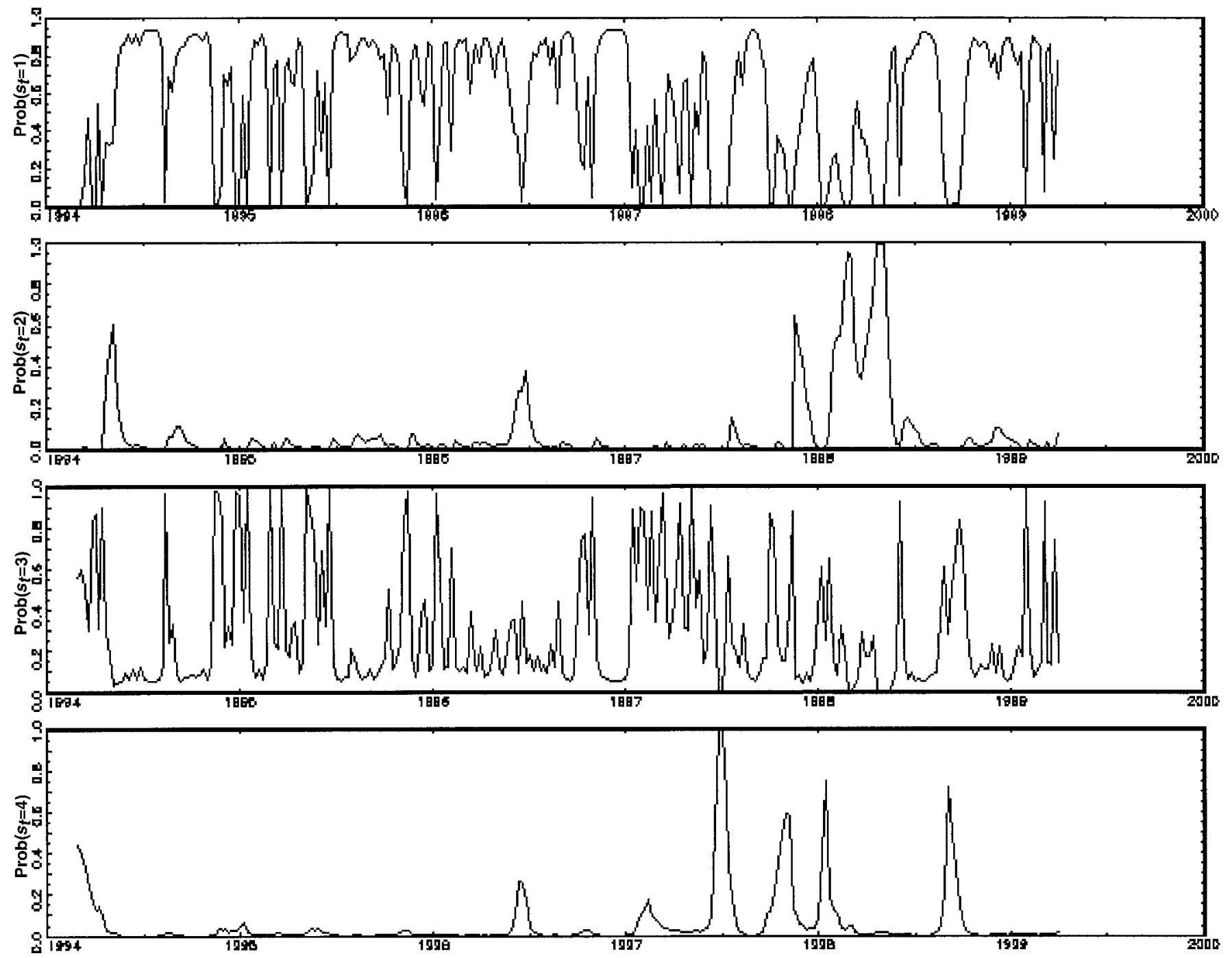

comovement or the volatility contagion hypotheses. In section IV of this paper we investigate formally the issue of volatility comovement in domestic nominal interest rates, by developing a multivariate SWARCH model.

\section{SWARCH and Rolling-Standard-Deviation Volatility Computations}

Some authors have argued that realized volatility measures provide an appropriate picture for the changing nature of volatility in financial markets (see Anderson et al., 2000, for example). In order to compare our SWARCH estimates with alternative volatility computations, we used daily data to construct two rolling standard deviations for each of our five countries. In the first one we used a 15 day rolling window; in the second one we used a 25 day window. In general, there are some (but only some) similarities between the rolling and the SWARCH measures of volatility.
To illustrate our calculations, in figures 8 and 9 we present four examples: Mexico, Hong Kong, Brazil, and Argentina. ${ }^{11}$ In each of these figures, we depict the rolling volatility standard deviation, constructed using a 25 day window. We compare these to the SWARCH volatility estimate. Consider first the case of Argentina. Although both measures capture changes in volatility, the SWARCH estimates capture sharper spikes in volatility. This is particularly the case in early 1995, when at the time of the Mexican tequila crisis Argentina was subject to major financial instability. The SWARCH spikes are also sharper in early 1991, around the time of the Russian crisis in mid 1998, and in early 1999 (at the time of the Brazilian crisis). The estimations for Mexico in figure 8 also show that the rolling-window and the SWARCH estimates capture the changing nature of volatility. The SWARCH estimates,

\footnotetext{
${ }^{11}$ The figures for the rest of the countries are available on request.
} 
Figure 13.-Bivariate SWARCH Model: Hong Kong-Argentina
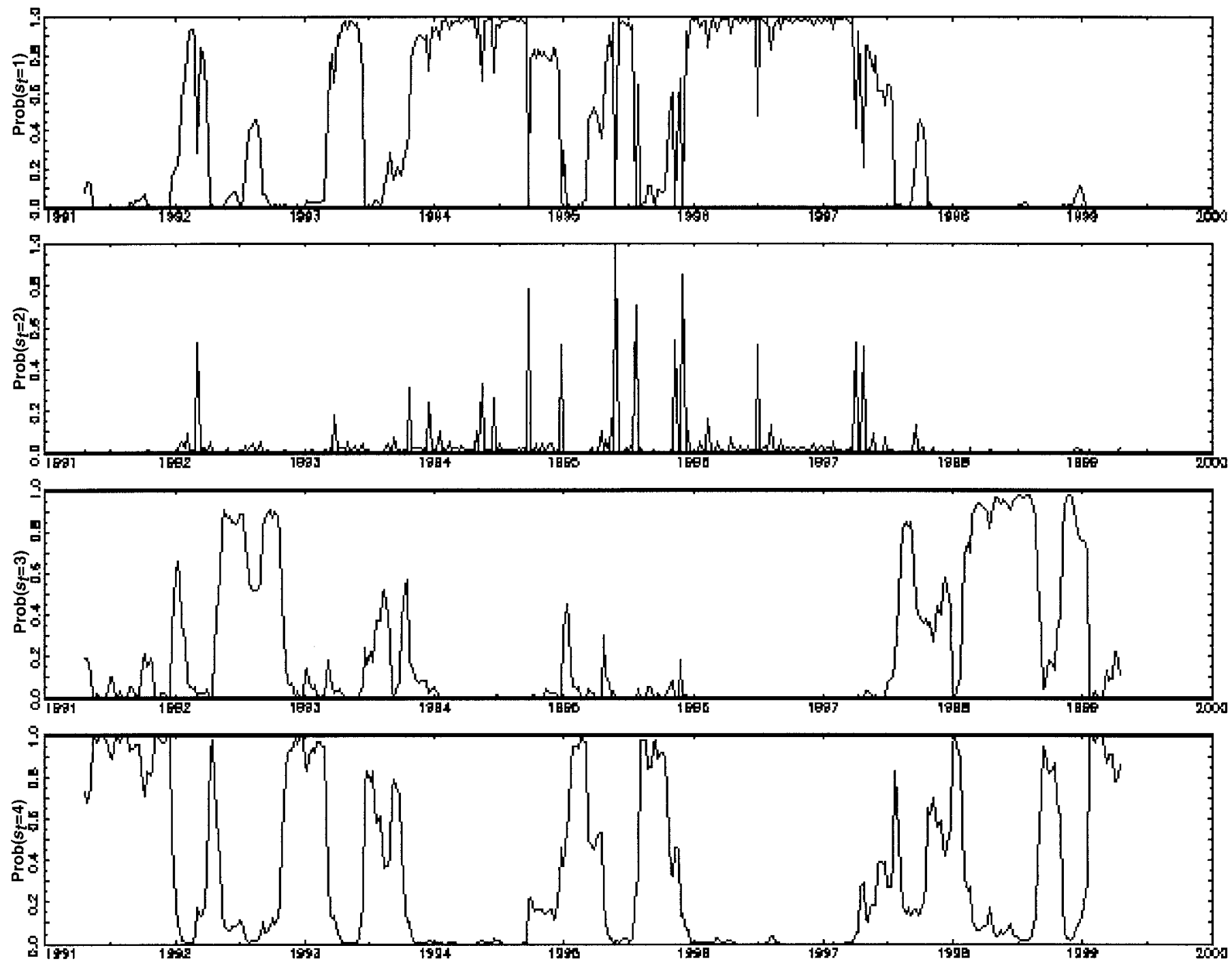

however, suggest that Mexican interest rates were in a high-volatility state for a longer period of time. Given that the true variance process is unobservable, it is not possible in this case to compare formally the rolling-window and SWARCH estimates. ${ }^{12}$ Overall, we believe that the ability to date volatility switches formally makes SWARCH estimates a useful tool for the analysis-a tool that, in general, should complement rather than replace rolling-window estimates.

\footnotetext{
${ }^{12}$ Note that under correct specification, the SWARCH volatility estimates are the maximum likelihood estimates. Thus, under correct specification, the rolling-window estimates do not estimate the variance as precisely as the SWARCH estimates. The rolling-window estimates are robust, however, to certain kinds of model misspecification. The rollingwindow estimates also provide an informal evaluation of the SWARCH estimates. A formal comparison would require some type of Monte Carlo exercise. This type of analysis, however, is beyond the scope of this paper.
}

\section{A Multivariate Analysis of Interest-Rate Volatility Switches}

In this section, we develop a multivariate switching volatility model to investigate formally whether interest-rate volatility switches coincide across countries. More specifically, we take advantage of the dating abilities of Hamilton's (1989) filter to test whether volatility states are independent across countries. As it turns out, multivariate SWARCH models are extremely intensive in computation time. For this reason the researcher has to make some choices in the number of volatility states and number of countries included in the analysis. In order to keep the number of parameters tractable, in this section we consider the case of two countries and two volatility states (high and low volatility).

In order to organize the discussion and reduce the dimensionality of the problem, we concentrate on the Mexican and East Asian crises. More specifically, we focus on Mexico- 
Figure 14.-Bivariate SWARCH Model: Hong Kong-Brazil
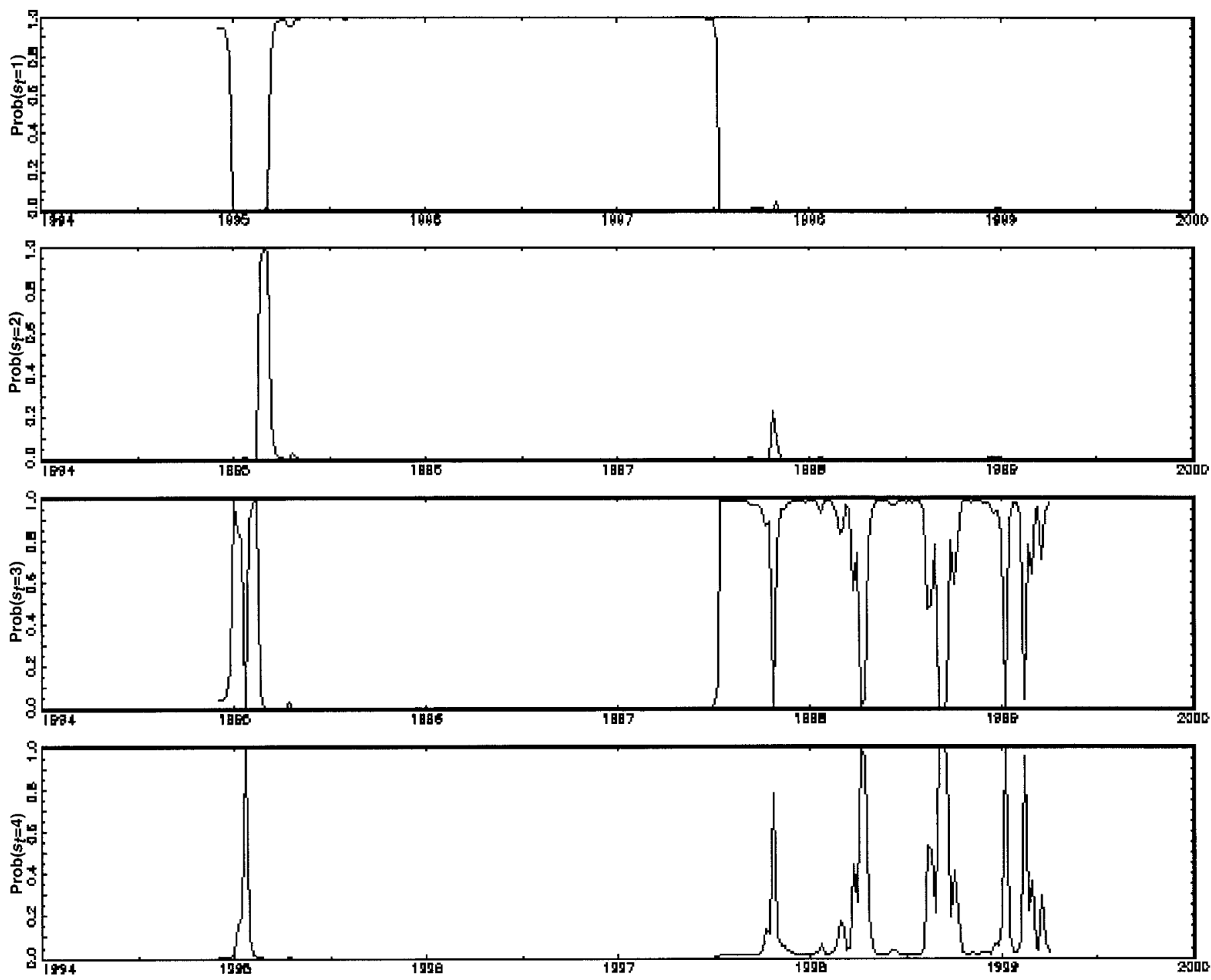

other-country and Hong Kong-other country pairs. By focusing on Mexico and Hong Kong-which we call (potential) volatility originators - we are able to explore the popular notion that the crises originated in those countries and spread into what were then called the "tequila effect" and the "Asian flu," respectively. ${ }^{13}$ Consider the case where we have two series (countries), with two volatility states. In this bivariate formulation, the number of states is four. For instance, with Hong Kong and Chile in a system, we have the following four primitive states, $s_{t}^{*}$.

$$
\begin{aligned}
& s_{t}^{*}=1 \text { : Hong Kong-low volatility; Chile-low volatil- } \\
& \text { ity. }
\end{aligned}
$$

${ }^{13}$ Of course, the Asian crisis could be dated a bit earlier, with the collapse of the Thai baht. However, as the data in figures 3 through 7 clearly show, no country in our sample suffered increased instability until the Hong Kong dollar was attacked by speculators in late October 1997. $s_{t}^{*}=2$ : Hong Kong-low volatility; Chile-high volatility.

$s_{t}^{*}=3$ : Hong Kong-high volatility; Chile-low volatility.

$s_{t}^{*}=4$ : Hong Kong-high volatility; Chile-high volatility.

The system can be written as

$$
\boldsymbol{r}_{t}=\boldsymbol{A}+\boldsymbol{B} \boldsymbol{r}_{t-1}+\boldsymbol{e}_{t}, \quad \boldsymbol{e}_{t} \mid I_{t-1} \sim N\left(0, \boldsymbol{H}_{t}\right),
$$

where $\boldsymbol{r}_{t}=\left[r_{t}^{x}, r_{t}^{y}\right]$ is a $2 \times 1$ vector of returns, $\boldsymbol{A}=\left[a_{x}\right.$, $\left.a_{y}\right]$ and $\boldsymbol{B}=\left[b_{x}, b_{y}\right]$ are $2 \times 1$ vectors, and $\boldsymbol{e}_{t}=\left[e_{t}^{x}, e_{t}^{y}\right]$ is a $2 \times 1$ vector of disturbances, which follow a bivariate normal distribution with zero mean and a time-varying conditional covariance matrix $\boldsymbol{H}_{t}$ (for notational convenience, we drop the dependence of $\boldsymbol{H}_{t}$ on the states of the economy). 
Figure 15.-Bivariate SWARCH Model: Hong Kong-Chile
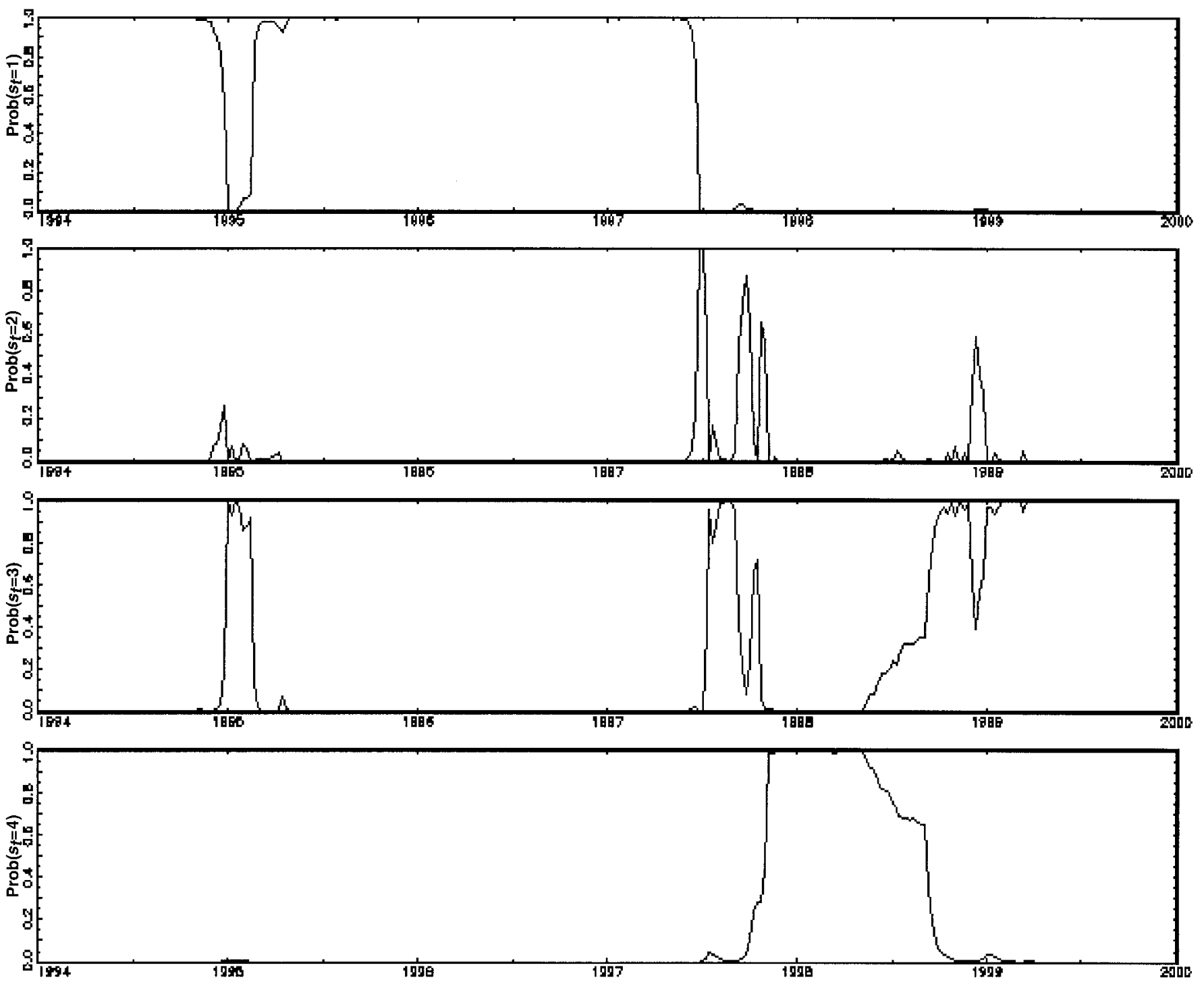

The conditional covariance matrix $\boldsymbol{H}_{t}$ is specified as a constant correlation matrix where the diagonal elements follow a SWARCH process. The correlation coefficient, $\rho_{s t}$, is state-dependent. That is, we allow the correlation coefficient to change with the volatility state of the originator country. ${ }^{14}$ This specification has been emphasized in the recent contagion literature, where the correlation coefficient between two markets changes significantly due to an unexpected increased in volatility in an originator country (see Forbes \& Rigobon, 1999, and Rigobon, 2001). Note, however, that the specification in equation (4) also allows the series $r_{t}^{x}$ and $r_{t}^{y}$ to be related through the nonlinearities associated with dependent states. This dependence might make the estimated states implied by the bivariate model different from those implied by the univariate model.

\footnotetext{
${ }^{14}$ In this analysis Mexico and Hong Kong are the two potential originator countries.
}

The probability law that causes the economy to switch among states is given by a $K^{*}=4$-state Markov chain, $P^{*}$, with a typical element given by $\operatorname{Prob}\left(s_{t}^{*}=j \mid s_{t-1}^{*}=i\right)=$ $p_{i j}^{*}$. In our four-state model, some of the $p_{i j}^{*}$ 's are close to zero, and in order to get convergence, we treat these parameters as given and equal to zero. This reduces the number of parameters to be estimated. As discussed in Hamilton and Lin (1996), this specification is very general and encompasses different interactions among the volatility states of both countries. That is, the transition probabilities (the $p_{i j}^{*}$ 's) could be restricted to fit different assumptions about the underlying volatility states. For example, in the case of $p_{24}^{*}$, if the volatility states of Hong Kong and Chile are independent, then $p_{24}^{*}=p_{12}^{\mathrm{HK}} p_{22}^{\mathrm{CH}}$. On the other hand, if the Hong Kong volatility states are shared by Chile, then $p_{24}^{*}=0$.

We first estimate the unrestricted model, together with the smoothed probabilities for the four states $s_{t}^{*}=j(j=1,2$, 
Figure 16.-Bivariate SWARCH Model: Hong Kong-MeXico
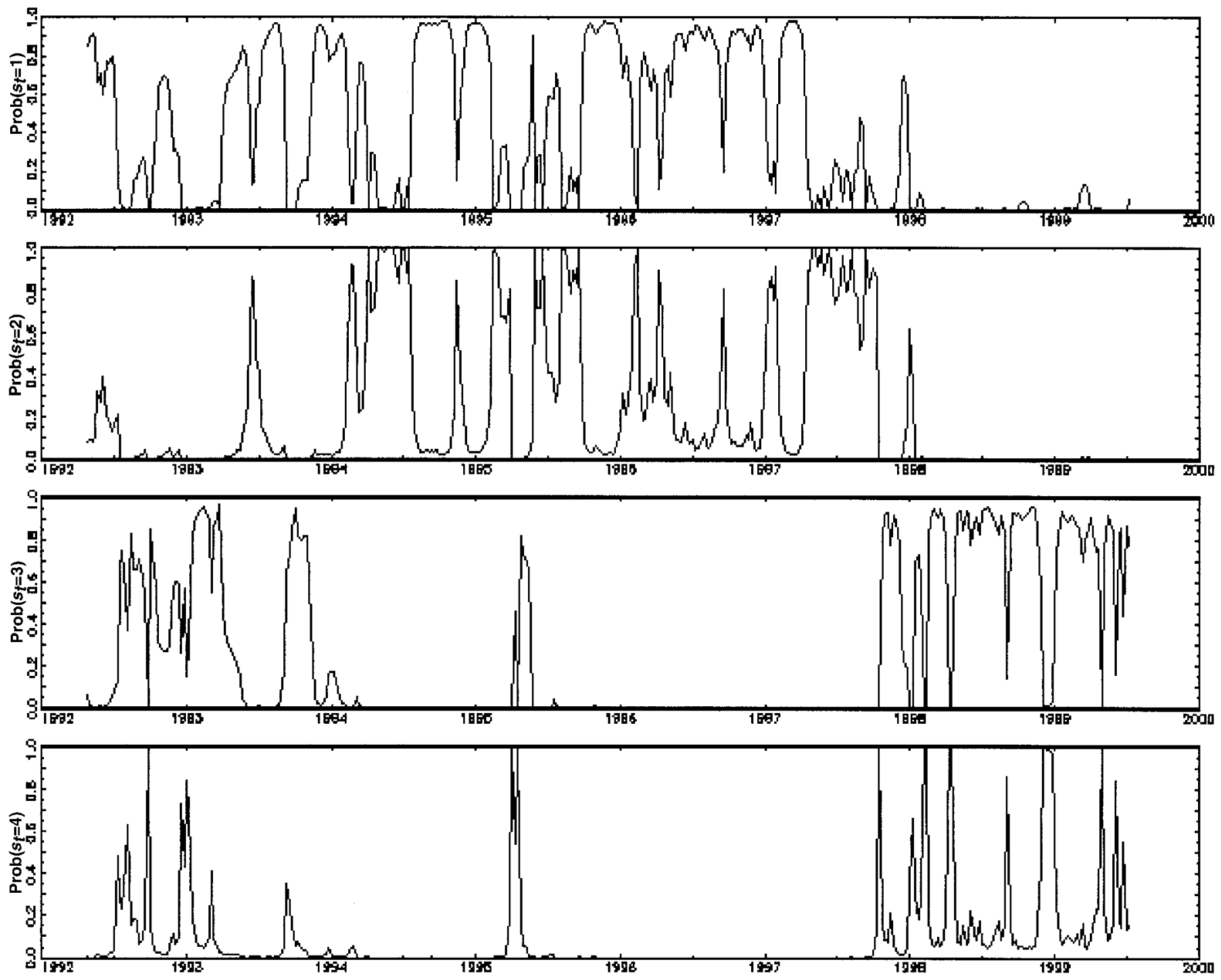

3 , 4) described above. We are particularly interested in determining whether pairs of countries are jointly in the high-high volatility state, and more specifically we are interested in finding out whether this occurs around the time of the currency crises of the 1990s. Second, we test formally whether the volatility states are independent across pairs of countries. And finally, for those cases where the null hypothesis of independence is rejected, we test whether, when the originator is in a high-volatility state, the recipient is also in the high-volatility state. This is a very strong test of volatility synchronization.

In order to test the null hypothesis of independent states, we first estimate a bivariate SWARCH model, imposing no restriction on the matrix $P^{*}$. The unrestricted model $\log$ likelihood function is denoted by $L\left(H_{A}\right)$. We then estimate the model by imposing the restricted transition probability matrix $P^{*}$ with elements such as $p_{14}^{*}=p_{12}^{x} p_{12}^{y}$. From this estimation, we obtain the log likelihood function of the restricted model, $L\left(H_{0}\right)$. From this in turn we can compute a likelihood ratio test, $L R=-2\left[L\left(H_{0}\right)-L\left(H_{A}\right)\right]$. Under the null hypothesis, this test has a $\chi^{2}$ distribution with $k$ degrees of freedom, where $k$ is given by the number of additional parameters estimated under the alternative hypothesis.

In figures 10 through 16 we present the estimated smooth probabilities corresponding to each of the four $s_{t}^{*}$ states described above. Figures 10-12 correspond to Mexico as the potential originator country, and figures 13-16 to Hong Kong. Each of these figures includes four panels: The first panel presents the probability that both countries are jointly in a low-volatility state. The second presents the probability that Mexico is in a high state and Argentina in a low state. The third presents the probability that Mexico is in a low state and Argentina in a high state. Finally, the fourth panel presents the probability that both countries are in a high volatility state. These figures show that, for most pairs of 
Table 5.-Mexico Originator: SWARCH(2,1) Bivariate System

\begin{tabular}{|c|c|c|c|}
\hline \multirow[b]{2}{*}{ Parameter } & \multicolumn{3}{|c|}{ Coefficient (Standard Error) } \\
\hline & Receptor ARS & Receptor BRR & Receptor CLP \\
\hline$a_{M, 0}$ & $-0.639(0.31)^{*}$ & $-1.169(0.43)^{*}$ & $-0.815(0.36)^{*}$ \\
\hline$a_{M, 1}$ & $-0.089(0.05)$ & $0.070(0.04)$ & $-0.061(0.05)$ \\
\hline$\alpha_{M, 0}$ & $20.262(3.49) *$ & $20.734(14.85)$ & $17.093(4.65)^{*}$ \\
\hline$\alpha_{M, 1}$ & $0.001(0.08)$ & $0.001(0.49)$ & $0.001(0.08)$ \\
\hline$\gamma_{M, 2}$ & $9.719(1.88)^{\dagger}$ & $14.595(3.69)^{\dagger}$ & $17.093(3.43)^{\dagger}$ \\
\hline$a_{\mathrm{Rec}, 0}$ & $0.553(0.23)^{*}$ & $0.090(0.04)^{*}$ & $-0.012(0.04)^{*}$ \\
\hline$a_{\operatorname{Rec}, 1}$ & $0.215(0.06)^{*}$ & $0.124(0.06)^{*}$ & $0.117(0.07)$ \\
\hline$\alpha_{\operatorname{Rec}, 0}$ & $11.193(1.49)^{*}$ & $0.231(0.03)^{*}$ & $0.245(0.03)^{*}$ \\
\hline$\alpha_{\operatorname{Rec}, 1}$ & $0.262(0.08)^{*}$ & $0.110(0.09)$ & $0.347(0.11)^{*}$ \\
\hline$\gamma_{\mathrm{Rec}, 2}$ & $10.739(5.38)^{\dagger}$ & $31.35(11.74)^{\dagger}$ & $7.512(2.13)^{\dagger}$ \\
\hline$\rho_{M-\mathrm{LV}}$ & $0.091(0.07)$ & $0.095(0.12)$ & $0.008(0.09)$ \\
\hline$\rho_{M-\mathrm{HV}}$ & $0.190(0.10)$ & $0.170(0.18)$ & $-0.108(0.12)$ \\
\hline $\begin{array}{l}\text { Likelihood, } \\
\text { SWARCH }\end{array}$ & -2481.1 & -1025.8 & -1231.4 \\
\hline $\begin{array}{l}\text { Likelihood, } \\
\text { independent state }\end{array}$ & -2488.9 & 1029.1 & -1233.5 \\
\hline $\begin{array}{l}\text { LR, independent } \\
\text { states ( } p \text {-value) }\end{array}$ & $14.4(0.0485)$ & $6.6(0.580)$ & $5.0(0.625)$ \\
\hline $\begin{array}{l}\text { Likelihood, high- } \\
\text { volatility } \\
\text { synchron. } \\
\text { LR, high-volatility } \\
\text { synchron. ( } p \text { - } \\
\text { value) }\end{array}$ & $21.0(0.0018)$ & - & - \\
\hline
\end{tabular}

countries, state 1 (low, low) is the most frequent one. In order to concentrate on the transmission of high volatility across countries, in the discussion that follows we focus, mostly, on the fourth panel for each pair of countries.

The results are quite interesting. Although there are several instances when interest rates in Mexico and Argentina are jointly in a high volatility state, this happens only once for Mexico and Brazil (in March 1995). Figure 12 confirms that Chile and Mexico did not jointly experience high interest-rate volatility states during the so-called tequila episode of 1994-1995. There are some spikes in the highhigh Mexico-Chile joint probability in later years, but they are few, and only in two weeks (in 1997) did the probability reach 1 . We interpret these joint high-high periods as responding to exogenous events (the Russian and East Asian crises) jointly affecting both countries.

Figure 13 shows that, since 1991, domestic-currency interest rates in Argentina and Hong Kong have jointly experienced high-volatility states-that is, $\operatorname{prob}\left(s_{t}^{*}=4\right)>$ 0.5 -during a number of periods. This figure also shows that in the latter part of 1997 Hong Kong and Argentina were jointly in the high-volatility state. According to figure 14, after the attack on the Hong Kong currency board in October 1997, domestic interest rates in Brazil and Hong Kong experienced short periods of joint high volatility. Throughout 1998, both countries also experienced joint high-high periods.
Table 6.-Hong Kong Originator: SWARCH(2,1) Bivariate System

\begin{tabular}{|c|c|c|c|}
\hline \multirow[b]{2}{*}{ Parameter } & \multicolumn{3}{|c|}{ Coefficient (Standard Error) } \\
\hline & Receptor ARS & Receptor BRR & Receptor CLP \\
\hline$a_{\mathrm{HK}, 0}$ & $0.285(0.25)$ & $0.035(0.25)$ & $0.194(0.24)$ \\
\hline$a_{\mathrm{HK}, 1}$ & $-0.241(0.07)^{*}$ & $0.232(0.06)^{*}$ & $-0.15(0.04)^{*}$ \\
\hline$\alpha_{\mathrm{HK}, 0}$ & $12.628(3.49)^{*}$ & $7.948(1.00)^{*}$ & $9.301(1.09)^{*}$ \\
\hline$\alpha_{\mathrm{HK}, 1}$ & $0.197(0.09)^{*}$ & $0.001(0.09)$ & $0.001(0.09)$ \\
\hline$\gamma_{\mathrm{HK}, 2}$ & $20.09(3.23)^{\dagger}$ & $54.058(10.32)^{*}$ & $49.520(9.23)^{\dagger}$ \\
\hline$a_{\operatorname{Rec}, 0}$ & $-0.583(0.24)^{*}$ & $-0.085(0.03)^{*}$ & $-0.021(0.04)$ \\
\hline$a_{\mathrm{Rec}, 1}$ & $0.173(0.05)^{*}$ & $0.132(0.05)^{*}$ & $0.118(0.07)$ \\
\hline$\alpha_{\operatorname{Rec}, 0}$ & $13.791(2.18)^{*}$ & $0.225(0.34)^{*}$ & $0.245(0.04)^{*}$ \\
\hline$\alpha_{\operatorname{Rec}, 1}$ & $0.391(0.10)^{*}$ & $0.113(0.09)$ & $0.348(0.11)^{*}$ \\
\hline$\gamma_{\text {Rec }, 2}$ & $11.955(2.48)^{\dagger}$ & $36.396(14.28)^{\dagger}$ & $7.349(2.11)^{\dagger}$ \\
\hline$\rho_{H-\mathrm{LV}}$ & $0.119(0.08)$ & $-0.057(0.09)$ & $-0.046(0.08)$ \\
\hline$\rho_{H-\mathrm{HV}}$ & $0.069(0.09)$ & $0.142(0.10)$ & $-0.0957(0.11)$ \\
\hline $\begin{array}{l}\text { Likelihood, } \\
\text { SWARCH }\end{array}$ & -2802.3 & -989.7 & -1168.1 \\
\hline $\begin{array}{l}\text { Likelihood, } \\
\text { independent } \\
\text { state }\end{array}$ & -2806.7 & 997.3 & -1174.3 \\
\hline $\begin{array}{l}\text { LR, independent } \\
\text { states ( } p \text {-value) }\end{array}$ & $7.2(.3594)$ & $15.2(.0096)$ & $12.4(.0350)$ \\
\hline $\begin{array}{l}\text { Likelihood, high- } \\
\text { volatility } \\
\text { synchron. } \\
\text { LR, high- } \\
\text { volatility } \\
\text { syncrhon. ( } p \text { - } \\
\text { value) }\end{array}$ & - & $70.2(<0.0001)$ & $7.9(0.0193)$ \\
\hline
\end{tabular}

Figure 15, on Hong-Kong and Chile, is probably the most interesting of them all. As may be seen, between 1994 and late 1997 there is no evidence of interest rates in the two countries jointly experiencing high-volatility states. And then, in October 1997, the probability of state $s_{t}^{*}=4$ jumps to 1 and stays there. This unusual event is as close as we can

Table 7.-Hong Kong And MeXiCO-SWARCH(2,1) Bivariate System

\begin{tabular}{|c|c|}
\hline Parameter & Coefficient \\
\hline$a_{\mathrm{H}, 0}$ & $10.185(0.24)$ \\
\hline$a_{\mathrm{H}, 1}$ & $0.241(0.06)^{*}$ \\
\hline$\alpha_{H, 0}$ & $12.605(1.73)^{*}$ \\
\hline$\alpha_{H, 1}$ & $0.246(0.10)$ \\
\hline$\gamma_{H, 2}$ & $25.498(4.48)^{\dagger}$ \\
\hline$a_{M, 0}$ & $-0.705(0.30)^{*}$ \\
\hline$a_{M, 1}$ & $-0.072(0.04)$ \\
\hline$\alpha_{M, 0}$ & $17.541(4.10)^{*}$ \\
\hline$\alpha_{M, 1}$ & $0.001(0.10)$ \\
\hline$\gamma_{M, 2}$ & $11.727(2.32)^{\dagger}$ \\
\hline$\rho_{M-\mathrm{LV}}$ & $0.003(0.07)$ \\
\hline$\rho_{M-\mathrm{HV}}$ & $0.048(0.10)$ \\
\hline Likelihood, SWARCH & -2573.0 \\
\hline Likelihood, independent states & -2576.6 \\
\hline LR, independent states ( $p$-value) & $7.2(.5152)$ \\
\hline
\end{tabular}


think to contagion. Figure 16 looks at Mexico and Hong Kong, our two originators. As may be seen, we find evidence of joint high volatility only during the East Asian crisis period.

Tables 5 to 7 present the estimated bivariate SWARCH parameters for each country, as well as the state-dependent correlation coefficients. These tables also report the likelihood ratio test for the null hypothesis that the volatility states are independent across each pair of countries. The independence state hypothesis is rejected for MexicoArgentina, Hong Kong-Brazil, and Hong Kong-Chile. That is, even though the correlation coefficient is not significantly different than zero in all states, we find a dependence between the interest-rate volatility states of these countries. For these three pair of countries we then tested the stronger null hypothesis of high-volatility synchronization discussed above. In tables 5 and 6 , we report these tests. As may be seen from these tables, we reject the hypothesis that when the originator is in the high-volatility state, the recipient is always in the high-volatility state. ${ }^{15}$

\section{Concluding Remarks}

We interpret the results presented in this paper as providing evidence of significant interconnection across financial markets in the emerging nations. What is particularly interesting is that these connections go beyond geographical proximity. For example, we find evidence that the volatility increased to high at approximately the same time in Hong Kong and Chile. In fact, as we showed in figure 13, in October 1997 the probability of Hong Kong and Chile being jointly in a high volatility state jumped to 1 and stayed at that level for several weeks. Indeed, the formal likelihood ratio test reported in table 7 rejects the hypothesis of volatility independence for Hong Kong and Chile. Similarly, our results for Mexico and Argentina support the notion of financial interconnectedness between these two nations' financial markets. The probability of both nations being jointly in the high-volatility state jumps to 1 at the times of the Chiapas incident, the Mexican devaluation, the Hong Kong crisis, and the Brazilian devaluation. The hypothesis of independence of volatility in Mexico and Argentina is rejected formally.

Finally, we note that even in those pairs of countries where the hypothesis of independence was not rejected formally, we were able to detect some episodes of joint moves to the high-volatility state. This is the case, for instance, of Mexico and Brazil in early 1995 at the time of the tequila crisis, and in 1998 after the Russian and LTCM episodes. It is also the case of Mexico and Chile after 1997: Indeed, we detected joint moves to the high-volatility state

\footnotetext{
${ }^{15}$ We also tested an even stronger version of the high-volatility synchronization hypothesis, the common-states hypothesis. Under this null hypothesis, both countries share the same volatility states. The commonstates null hypothesis was rejected in all the cases, with a $p$-value lower than 0.0001 .
}

the second half of 1997 and early 1998 (East Asian crisis), as well as in mid 1998 (Russia and LTCM).

\section{REFERENCES}

Andersen, T., T. Bollerslev, F. X. Diebold, and P. Labys, "Understanding, Optimizing, Using, and Forecasting Realized Volatility and Correlation," Risk 12 (2000), 105-108.

Ball, C., and W. Torous, "Regime Shifts in Short Term Riskless Interest Rates," The Anderson School, UCLA, working paper no. 15-95, (1995).

Bennet, P., and J. Kelleher, "The International Transmission of Stock Price Disruption in October 1987," Federal Reserve Bank of New York Quarterly Review, 13 (summer 1988), 17-33.

Cai, Jun, "A Markov Model of Unconditional Variance in ARCH," Journal of Business and Economic Statistics, 12 (1994), 309-316.

Campbell, J. Y., A. Lo, and MacKinlay, The Econometrics of Financial Markets (Princeton University Press, 1997).

Edwards, S., "Interest Rate Volatility, Contagion and Convergence: An Empirical Investigation of the Cases of Argentina, Chile and Mexico," Journal of Applied Economics 1 (1998), 55-86.

Edwards, S., and R. Susmel, "Volatility Dependence and Contagion in Emerging Equity Markets," Journal of Development Economics, 66, (December 2001), 505-532.

Engle, R. F., and V. K. Ng, "Measuring and Testing the Impact of News on Volatility," Journal of Finance 48 (1993), 1749-1778.

Engle, R. F., T. Ito, and W.-L. Lin, "Meteor Shower or Heat Waves. Heteroskedastic Intra-daily Volatility in the Foreign Exchange Market," Econometrica 55 (May 1990), 525-542.

Forbes, K., and R. Rigobon, "No Contagion, Only Interdependence: Measuring Stock Market Co-movements," NBER working paper no. 7267 (1999).

Ghysels, E., and S. Ng, "A Semiparametric Factor Model of Interest Rates and Tests of the Affine Term Structure," Review of Economic Statistics 80 (1998), 535-548.

Glosten, L. R., R. Jaganathan, and D. Runkle, "Relationship between the Expected Value and the Volatility of the Nominal Excess Return on Stocks," Journal of Finance 48 (1993), 1779-1801.

Gray, S., "Modeling the Conditional Distribution of Interest Rates as a Regime Switching Process," Journal of Financial Economics 42 (1996), 27-62.

Hamao, Y., R. Masulis, and V. Ng, "Correlations in Price Changes and Volatility across International Stock Markets," Review of Financial Studies 3 (1990), 281-308.

Hamilton, James D., "A New Approach to the Economic Analysis of Nonstationary Time Series and the Business Cycle," Econometrica 57 (1989), 357-384.

— "Specification Testing in Markov-Switching Time Series Models," Journal of Econometrics, (1996), forthcoming.

Hamilton, James D., and R. Susmel, "Autoregressive Conditional Heteroskedasticity and Changes in Regime," Journal of Econometrics 64 (1994), 307-333.

Hamao, Y., R. Masulis, and V. Ng, "Correlations in Price Changes and Volatility across International Stock Markets," Review of Financial Studies, 3 (1990), 281-308.

Hansen, B. E., "The Likelihood Ratio Test under Non-standard Conditions: Testing the Markov Trend Model of GNP," Journal of Applied Econometrics 7 (1992), S61-S82.

_ "Erratum: The Likelihood Ratio Test under Non-standard Conditions: Testing the Markov Trend Model of GNP," Boston College working paper (1994).

Kalimipalli, M., and R. Susmel, "Switching Stochastic Volatility, TwoFactor Models and Term Structure," University of Houston, unpublished manuscript (1999).

King, M., and S. Wadhwani, "Transmission of Volatility between Stock Markets," Review of Financial Studies, 3 (1990), 5-33.

Krugman, P., "Depression Economics Returns," Foreign Affairs 78 (1999), 1.

Lamoreux, C. G., and W. D. Lastrapes, "Persistence in Variance, Structural Change and the GARCH Model," Journal of Business and Economic Statistics, 5 (1990), 121-129.

Lanne, M., "An Investigation of the Risk and Return Relation at Long Horizons," Review of Economics and Statistics, 81 (1999), 393398. 
Ljung, G., and G. Box, "On a Measure of Lack of Fit in Time Series Models,” Biometrika, 65 (March 1978), 297-303.

Longin, F., and B. Solnik, "Is the Correlation in International Equity Returns Constant: 1960-1990?" Journal of International Money and Finance, 14 (1995), 3-23.

Ramchand, L., and R. Susmel, "Cross Correlations across Major International Markets," Journal of Empirical Finance 5 (1998), 397-416.

Reinhart, C., "Fear to Float," American Economic Review (May 2000), 65-70.
Rigobon, R., "Contagion: How to Measure It?" (pp. 269-334), in Sebastian Edwards and Jeffrey Frankel (Eds.), Preventing Currency Crises in Emerging Markets, (Chicago: University of Chicago Press, 2002).

Ruge-Murcia, F., "Credibility and Changes in Policy Regime," Journal of Political Economy, 103 (1995), 176-208.

Stiglitz, J., "Bleak Growth Prospects for the Developing World," International Herald Tribune (April 10-11, 1999), 6. 